\title{
Intra-Household Allocation of Parental Leave
}

P. Gobbi, J. Parys and G. Schwerhoff

Discussion Paper 2015-20

Institut de Recherches Économiques et Sociales de l'Université catholique de Louvain

IRES 


\title{
Intra-Household Allocation of Parental Leave*
}

\author{
Paula E. Gobbi ${ }^{\dagger} \quad$ Juliane Parys ${ }^{\ddagger} \quad$ Gregor Schwerhoff ${ }^{\S}$
}

November 24, 2015

\begin{abstract}
We introduce childcare sharing in a collective model of household behavior to investigate which factors make spouses increase or decrease their share of parental leave. The concern about future consumption motivates parents to invest in their human capital and to limit their leave duration. Using relative income and the age difference between spouses as distribution factors, we cannot reject Pareto efficiency in childcare sharing. Higher relative incomes and larger age differences shift the conditional leave allocation towards the relatively poorer and younger partner, respectively. Households with higher total income purchase more professional childcare.
\end{abstract}

JEL classification: D13, J12, J13.

Keywords: Childcare sharing, parental leave, collective model, sharing rule, gender

*The authors wish to thank David Card, Pierre-André Chiappori, Martin Hellwig and Monika Merz for insightful discussions and comments. All remaining errors are our own.

${ }^{\dagger}$ Corresponding author, National Fund for Scientific Research (Belgium) and IRES, Université catholique de Louvain, Belgium, email: paula.gobbi@uclouvain.be

${ }_{\ddagger}^{\ddagger}$ McKinsey \& Company

$\S$ Mercator Research Institute on Global Commons and Climate Change (MCC), Torgauer Str. 12-15, 10829 Berlin, Germany, email: schwerhoff@mcc-berlin.net. 


\section{Introduction}

Long labor market absence after the birth of a child causes a durable income and career penalty due to, e.g., forgone growth of human capital and a negative work commitment signal to the employer. ${ }^{1}$ Traditionally, this has mainly been borne by mothers. ${ }^{2}$ However, the allocation of childcare time, as far as it conflicts with market work, is increasingly subject to change especially in countries with a generous paid leave legislation. In this study, we model which factors lead spouses to increase or decrease their individual parental leave share. The concern about future income incentivizes parents to reduce their individual job absence as much as possible while at the same time assuring the well-being of the newborn.

Treating a multiple-person household as a rational entity with a single set of goals has been rejected by many economists. ${ }^{3}$ This is especially important for our study as it aims to gain insight into the process that determines how parents share the time they spend on doing childcare instead of working on the labor market. As an alternative to unitary household models, Chiappori $(1988,1992)$ and Apps and Rees (1988) are the first to propose the most general form of a collective model of household behavior. The key assumption is that, however household decisions are made, the outcome is Pareto efficient. Browning and Chiappori (1998), Chiappori, Fortin, and Lacroix (2002), and Chiappori and Ekeland (2006) extend this model by including distribution factors that affect household decisions even though they do not have a direct impact on preferences nor on budgets. The existence of distribution factors is crucial for the model's testability. Blundell, Chiappori, and Meghir (2005) interpret the solution to the household problem as a two-stage process, where household members share what is left for private consumption after purchasing a public good.

\footnotetext{
${ }^{1}$ Some of the early references are Mincer and Polachek (1974) as well as Corcoran and Duncan (1979). For the German case and the relevant duration of labor market absence this has been documented by (Schönberg and Ludsteck 2014).

${ }^{2}$ Ruhm (1998) reveals that brief parental leave periods (3 months) have little effect on women's earnings, but lengthier leave (9 months or more) is associated with substantial and durable reductions in relative wages within Western European countries. Erosa, Fuster, and Restuccia (2002) find that fertility decisions generate important long-lasting gender differences in employment and wages that account for almost all the U.S. gender wage gap that is attributed to labor market experience.

3 A convincing empirical example is Lundberg, Pollak, and Wales (1997).
} 
The collective framework nests any axiomatic bargaining approach that takes efficiency as an axiom. For instance, the Nash bargaining solution can be expressed as a maximization of the product of individual surpluses. Each agent's surplus involves the agent's status quo value which varies with personal characteristics and distribution factors. As pointed out in Bourguignon, Browning, and Chiappori (2009), any efficient intra-household allocation can be constructed as a bargaining solution for well-chosen status quo points.

Applications of the collective model to parental leave sharing are rare in the literature. One example is Amilon (2007), who analyzes temporary leave sharing in Sweden using a Stackelberg bargaining model with a first-mover advantage for men due to an unexplained "cultural factor". In the empirical literature, the effect of different parental benefit schemes across countries on parents' childcare time contributions has been analyzed. Ekberg, Eriksson, and Friebel (2013), e.g., evaluate the introduction of a "daddy month" in Sweden and find an increase of fathers' childcare time contribution, but no learning-by-doing effect for childcare.

Generous parental leave benefits as introduced in many European countries stabilize household incomes after the birth of a child no matter who interrupts the professional career in favor of providing childcare. Shortening parental leave periods is therefore mainly motivated by long-term career concerns impacting the future distribution of power between partners. An endogenization of gender power has been theoretically explored by Basu (2006), Iyigun and Walsh (2007a) and Iyigun and Walsh (2007b).

We apply the basic theoretical framework described before and introduce childcare sharing to a collective model of household behavior with public consumption as in Blundell, Chiappori, and Meghir (2005). The model does not assume any innate asymmetry between partners. It intends to explain the mechanism behind intra-household allocation of childcare time and consumption while assuming Pareto optimality of the outcome. Couples maximize a weighted sum of individual utilities. The Pareto weights have a clear interpretation as "distribution of power" parameters. Parents can purchase professional childcare to reduce the total leave duration of the household. This allows them to participate in the labor market and invest in 
human capital, thus increasing household consumption in the future. In this sense professional childcare is a public good.

Our model focuses on two main trade-offs involved with the intra-household allocation of parental leave. The first, concerns the consumption allocation between partners. Childcare provided by a parent him- or herself reduces that parent's market working time, but allows the other partner to take less leave. Although income is to a large extent replaced through parental benefit, parenthood-related job absence nevertheless involves an income penalty after returning to work compared to a situation without any career interruption. The second major trade-off we consider is between consumption during the period right after birth, when the newborn needs intensive care, and later on. Parents can hire professional childcare such as nannies or daycare facilities and reduce total household leave time. The more professional childcare parents purchase, the more it reduces the household's private consumption in period 1, but the more it allows partners to work and accumulate human capital for the second period.

The empirical restrictions of the model are tested using survey data on young German families provided by the Rhine-Westphalia Institute for Economic Research Essen (2008). ${ }^{4}$ We first address the theoretical assumption of the Pareto efficient allocation on parental leave. Bourguignon, Browning, and Chiappori (2009) provide testable restrictions based on the presence of distribution factors which we exploit to empirically test collective rationality in parental leave sharing. Applying the proportionality condition from Bourguignon, Browning, and Chiappori (2009), the first important result we can take from the data is that we cannot reject Pareto efficiency in leave sharing.

The empirical analysis also allows us to support the following theoretical implications. First, an increase in a distribution factor that increases one partners Pareto weight decreases this partner's parental leave and increases that of the spouse. This is true when considering relative wages and age differences between spouses as distribution factors. The second prediction from

\footnotetext{
${ }^{4}$ The German legislation allows both parents to go on paid leave and receive generous benefits replacing 67-100 percent of the average monthly net income from before the child's birth. The law allows leave time allocation between parents to be relatively flexible.
} 
the theory is that an increase in one partner's income, strengthens this partner's power in the household and allows him or her to shift some leave time to the spouse. But the net effect on the spouse's leave duration is not straightforward. On the one hand, there is a wealth effect stemming from the household income increase, which allows the couple to purchase more professional childcare. On the other hand, the change in Pareto weights leads to a redistribution

of leave time between parents. For mothers, we estimate that doubling the mothers' earnings decreases her parental leave of about 1.4 months while it increases the fathers' leave time of almost a month. Third, the model predicts that parents with higher joint incomes purchase more professional childcare, but that it is independent of distribution factors. Finally, we suggest that the large difference between female vs. male parental leave duration is mainly explained by differences in Pareto weights, mainly due to the fact that in most households the man's relative wage is higher and the man is older than the woman.

The paper is organized as follows. Section 2 introduces a collective model of intra-household childcare and consumption sharing. An overview of the legal parental benefit situation in Germany in 2007 and a data description are provided in Section 3. In Section 4 we empirically test our collective model and its predictions. The last section concludes.

\section{A Collective Model of Parental Leave Sharing}

\subsection{Unitary, Collective and Non-Cooperative Household Models}

For decades, most theoretical and applied microeconomic work involving household decision making assumed that a household behaves as if it had a single set of goals. Following Browning and Chiappori (1998) we refer to them as unitary models. In a unitary household model the partners' utility functions represent the same preferences such that their joint utility is maximized under a budget constraint. More precisely, a weighted sum of utilities is maximized, but the weights are fixed. This does not take into consideration that spouses' interests might 
not always be aligned and that the degree to which a spouse can influence the household decision might depend on individual characteristics. Factors that neither enter individual preferences nor the overall household budget constraint but influence the decision process are known as distribution factors. A model with a weighted sum of individual utility functions is formally a unitary model as long as the weights do not depend on these distribution factors.

We apply a collective setting as in Blundell, Chiappori, and Meghir (2005) to study intrahousehold decision making about parental leave sharing where we explicitly model the conflict of interests between partners. To illustrate how unitary and collective models react differently, consider an increase in income of the woman. The additional income increases the household income. Through this wealth effect the couple can afford more professional childcare and to take less leave. In a unitary model both partners share the gain in market work time equally. The collective model on the other hand incorporates an additional effect - the bargaining effect. The woman's bargaining weight is strengthened, leading to a bigger share of household wealth for her. Wealth and bargaining effect work to her advantage in the considered case. The man benefits from the increased household wealth, but he suffers from a loss of bargaining power. For him, the net effect in terms of leave taking might be positive or negative, depending on the specific functional form of the household utility function.

In addition to cooperative household models like the unitary and collective approach, noncooperative models have been proposed in the literature. These models consider a conflict of interest between household members and the presence of distribution factors as well. However, they do not assume Pareto efficiency of the outcome. Instead, each household member maximizes his or her own utility independently while taking the utility-maximization process of the spouse as given. This way of resolving a conflict in the household has been advanced by Konrad and Lommerud (1995) among others. Konrad and Lommerud (1995) do not motivate the model as a general concept, but rather suggest it for specific uses such as modeling threat points in a cooperative model. One application is illustrated in the "semi-cooperative" model of Konrad and Lommerud (2000). The authors combine a non-cooperative period before the 
family is formed with a cooperative period afterwards.

An example for non-cooperative behavior between spouses has been provided by Duflo and Udry (2004) in Cote d'Ivoire. Gobbi (2014) provides an example of a non-cooperative model for the time spent with children. The inefficiency arises, because spouses cannot observe how much time the other actually spends with the child. Parental leave, however, can be observed easily so that the cooperative model can plausibly be applied.

\subsection{Model Setup}

We consider households composed by two agents, characterized by their gender $i=\{m, f\}$, respectively for male and female, their period specific wage rate $w_{t}^{i}$ and their previously acquired labor experience $h_{0}^{i}$. Households decide how to allocate their time and consumption goods resources over 2 periods, $t=1$ and $t=2$. During the first period, each agent has $T$ units of time to allocate between work and childcare. During this period parents also choose how much professional childcare time to buy in the market. ${ }^{5}$ The amount of childcare provided by one parent in the first period matters for his/her level of consumption in the next period. This reflects that work experience is valued as an input to human capital accumulation. A higher work experience increases income and consequently the individual consumption share in the second period. ${ }^{6}$

\section{Time constraints}

During period 1, each parent $i$ has to allocate time between market work $h_{1}^{i}$ and leave $b^{i}$ :

$$
T=h_{1}^{i}+b^{i}, \quad i=\{m, f\},
$$

where $h_{1}^{i}, b^{i} \in(0, T)$. The subscript indicates the period. Parental leave $b^{i}$ can only be taken in

\footnotetext{
${ }^{5}$ Our model does not include any explicit measure of leisure, because we focus on the extensive margin of labor supply.

${ }^{6}$ In addition, a long leave period might imply career drawbacks as it signals weak work commitment to the employer and promotion rounds might be missed.
} 
period 1 and does therefore not have a superscript. During the first period, childcare needs to be guaranteed permanently either by parents providing childcare themselves, denoted $b^{m}$ and $b^{f}$, or by hiring professional childcare, denoted $b^{p}$, such that

$$
T=b^{m}+b^{f}+b^{p} .
$$

Professional childcare is considered a public good that shortens the cumulative leave duration of both partners. ${ }^{7}$ During period 2, time is fully spent at work. We normalize time to 1 in this second period.

\section{Budget constraints}

We restrict the analysis to countries with generous paid leave regulations. For simplicity, we then assume parental benefit to compensate for all the immediate income loss parents encounter from going on leave since our model focuses on the long-term career drawbacks from parenthoodrelated job absence. ${ }^{8}$ Total income of partner $i$ is consequently given by $w_{1}^{i} \times T$ for period 1 and $w_{2}^{i}$ for period 2 .

We take the wage in the first-period $w_{1}^{i}$ as given, reflecting the level of human capital from education acquired up to the child's birth. The income level in period 2 depends on education (as reflected in first-period income), on labor market participation during period 1, and on the initial level of work experience, $h_{0}^{i}$. For all $i=\{m, f\}$ we then write

$$
w_{2}^{i}=\left(T-b_{1}^{i}+h_{0}^{i}\right) w_{1}^{i} .
$$

Contrary to the income of a partner in period 1 , income in period 2 , is affected by parental leave through the effect on work experience. This long-term consideration motivates spouses

\footnotetext{
${ }^{7}$ Modeling different childcare qualities is interesting, but not the focus of the current study. Therefore, we assume maternal, paternal, and professional childcare to be perfect substitutes.

${ }^{8}$ This assumption does not affect our results as long as the replacement of earnings does not depend on gender, which is the case in Germany. Direct income reductions during leave could be incorporated in the model through multiplying the wage of the parent on leave by an income reduction factor $\lambda \in(0,1) . \lambda=0$ reflects the situation of countries with unpaid parental leave, whereas our model assumes full income replacement, i.e. $\lambda=1$.
} 
to favor market work over childcare in the first period.

In period 1, parents can spend their income in two ways. They can either consume private goods, or purchase professional childcare at a price $w^{p}$. Parents are credit constrained so that consumption in the first period must be financed from current income:

$$
c_{1}^{m}+c_{1}^{f}+b^{p} w^{p}=T\left(w_{1}^{m}+w_{1}^{f}\right) .
$$

In period 2, the budget constraint is simply given by

$$
c_{2}^{m}+c_{2}^{f}=w_{2}^{m}+w_{2}^{f} .
$$

\section{Individual Utility}

Each parent derives utility from consumption and from the well-being of their child. The utility from having a child and its well-being explains a couple's demand for children. However, once the decision for having a child has been made, the derived utility is constant given that at least one person takes care of it. ${ }^{9}$ Thus, we model consumption in each of the two periods as the variables to be maximized. The instantaneous utility function for an individual $i$ is given as

$$
U_{t}^{i}=U\left(c_{t}^{i}\right)=\ln \left(c_{t}^{i}\right)
$$

Our model incorporates public and private consumption. As in Blundell, Chiappori, and Meghir (2005), partners share what is left for private consumption after purchasing a public good. The level of public consumption implicitly determines the amount of time parents can work on the market and accumulate human capital to positively impact future earnings. Since utility from the child's well-being is constant, professional childcare impacts utility only indirectly via the budget constraint. For the allocation of consumption, we focus on private consumption for

\footnotetext{
${ }^{9}$ See Chiappori and Weiss (2007) for an example of this assumption in the literature. Further support for this assumption comes from Dustmann and Schönberg (2012), which finds that expansions in leave coverage does not improve children's outcomes.
} 
two reasons. First, private consumption is especially important to both partners as it remains to a large extend even after a potential marital dissolution. Second, we want to investigate the impact of the intra-household distribution of power on consumption shares, and public consumption is not affected by changes in the power allocation.

\section{Couple's decision problem}

Spouses behave cooperatively and maximize a joint utility function, given by a weighted sum of utilities. The resulting allocation of household resources is assumed to be Pareto optimal.

The man's Pareto weight in period $t$ is denoted $\mu_{t} \equiv \mu\left(\mathbf{z}_{t}\right) \in[0,1]$ and the woman's $1-$ $\mu_{t} .{ }^{10}$ These weights reflect the power of each partner and depend on a 2-dimensional vector of distribution factors $\mathbf{z}_{t}$. Denoting by $a$ the difference between the man's age and the female's age, the man's weight in period $t$ is therefore given by $\mu_{t}=\mu\left(w_{t}^{m} / w_{t}^{f}, a\right)$. This implies that the man's weight $\mu_{t}$ increases when either one or both of its distribution factors, $w_{t}^{m} / w_{t}^{f}$ or $a$, increase. $^{11}$

The lack in technology to intertemporally transfer resources leads to a hold-up problem. In period 2, a second negotiation round takes place based on the Pareto weights in that period. In a fully efficient model spouses would maximize their joint intertemporal income and distribute it in a way that maximizes joint utility over both periods. This solution requires either the ability of unconstrained loans against future incomes or a credible commitment technology. We argue that fully efficient intertemporal maximization does not generally happen. If so, we should observe the better-earning spouse to take no leave at all since his or her investment in human capital is relatively more profitable in the long run. Either the other spouse would then need to be compensated for staying out of the labor market, or the working spouse would

\footnotetext{
${ }^{10}$ If $\mu\left(\mathbf{z}_{t}\right)=1$ the household behaves as though the man always gets his way, whereas if $\mu\left(\mathbf{z}_{t}\right)=0$ it is as though the woman were the effective dictator. For intermediate values, the household behaves as though each person has some decision power.

${ }^{11}$ Browning, Chiappori, and Weiss (2014) suggest that relative income $w_{t}^{m} / w_{t}^{w}$ is the number one distribution factor. Other examples for observable and unobservable distribution factors from the literature include relative incomes, age difference, relative physical attractiveness, and the local sex ratio. In the context of childcare, custody allocation and alimony transfers from the custody to the non-custody parent after divorce are further examples.
} 
need to be able to credibly commit to not exploiting his or her stronger bargaining weight in the second period. The first option would require large loans against future incomes. For the second option, the outside-marriage situation for the childcare-providing parent would need to be sufficiently good to provide a credible commitment device. However, we show in Table 1 that many couples choose an interior solution so that neither option seems to be feasible in practice.

We therefore assume that spouses choose cooperatively within a given period. Parents thus achieve constrained efficiency, meaning that efficiency is reached within periods, but not intertemporally. The lack of full transferability between periods, however, leads them to favor investments in their own future bargaining power rather over maximizing total household income. $^{12}$

Parents are engaged in a two-stage game. In period 1, they jointly decide about consumption and childcare shares based on their pre-determined Pareto weights. The resulting level of work experience determines the second-period bargaining weights which affects the allocation of consumption goods in that period. Consequently, bargaining weights in period 2 are endogenous as in Basu (2006), Iyigun and Walsh (2007a) and Iyigun and Walsh (2007b).

We solve this two-period decision problem by backward induction starting with period 2, taking the optimal choices of period 1 as given.

Using (6) the maximization problem of the couple in period 2 reads

$$
\max _{c_{2}^{m}, c_{2}^{f}} \mu_{2} U_{2}^{m}+\left(1-\mu_{2}\right) U_{2}^{f}
$$

This yields the optimal solutions $c_{2}^{m *}=\mu_{2}\left(w_{2}^{m}+w_{2}^{f}\right)$ and $c_{2}^{f *}=\left(1-\mu_{2}\right)\left(w_{2}^{m}+w_{2}^{f}\right)$.

The second-period solution depends on the outcome of period 1 in two ways: Total household income is the higher the less parental childcare has been provided in period 1 because of the

\footnotetext{
${ }^{12}$ This follows the conclusion of Mazzocco, Ruiz, and Yamaguchi (2014): "Household decisions are efficient, subject to the constraint that spouses cannot commit to future allocations of resources."
} 
positive impact of market work on human capital. This is the wealth effect. Since the secondperiod bargaining weight $\mu_{2}$ depends on relative income in period 2 , the bargaining effect describes the negative impact of parental leave in period 1 on the second-period consumption share because of the weaker bargaining power.

As in Iyigun and Walsh (2007b), we find that the full model with endogenous bargaining weights cannot be solved analytically. We therefore opt to simplify the model at this point by assuming that spouses rely exclusively on their own income in period 2 and not on the Pareto weights:

$$
c_{2}^{i}=w_{2}^{i}=\left(T-b_{1}^{i}+h_{0}^{i}\right) w_{1}^{i} .
$$

This conserves the concept that each spouse is concerned about its own future income, because it determines consumption.

In the first period, the couple chooses $h_{1}^{m}, h_{1}^{f}, b^{m}, b^{f}$ and $b^{p}$ to maximize a weighted sum of the lifetime utility of each of the partners (6), denoted by $\mathbb{L}$;

$$
\mathbb{L} \equiv \mu_{1}\left(U_{1}^{m}+U_{2}^{m}\right)+\left(1-\mu_{1}\right)\left(U_{1}^{f}+U_{2}^{f}\right)
$$

subject to the time constraints (1) and (2), the financial budget (4), the second-period consumption (8), and non-negativity constraints for all arguments. Assuming for the moment that the non-negativity constraints are binding, we obtain the following solution (see Appendix A.1 for details)

$$
\begin{aligned}
b^{f *} & =\left(1+\mu_{1}\right) \frac{h_{0}^{f}+T}{2}-\left(1-\mu_{1}\right) \frac{T\left(w_{1}^{m}+w_{1}^{f}\right)+h_{0}^{m} w^{p}}{2 w^{p}} \\
b^{p *} & =\frac{T\left(w_{1}^{m}+w_{1}^{f}\right)}{2 w^{p}}-\frac{h_{0}^{m}+h_{0}^{f}+T}{2} \\
c_{1}^{f *} & =\left(1-\mu_{1}\right) \frac{\left(w_{1}^{m}+w_{1}^{f}\right) T+w^{p}\left(T+h_{0}^{m}+h_{0}^{f}\right)}{2} .
\end{aligned}
$$

Spouse's consumption shares are increasing in household income and respective Pareto weights. 
This highlights the wealth and bargaining effect of any change in income. Since the weight is a function of relative income, any improvement in own education or work experience leads to an increase in the own consumption share.

\subsection{Results}

We summarize the results of the theory in the following four propositions. We focus on the effect of distribution factors. The proofs for this section can be found in Appendix A.2.

Proposition 1 A distribution factor z that strengthens (weakens) a partner's Pareto weight, decreases (increases) his/her optimal leave duration and increases (decreases) the leave duration of the spouse.

This proposition shows that the intra-household parental leave allocation depends on the distribution of power between partners and therefore on distribution factors. The leave allocation changes in favor of the spouse who gains power.

Proposition 2 The optimal leave duration of each parent decreases when his or her own firstperiod wage rate increases.
(i) $\frac{\partial b^{f *}}{\partial w_{1}^{f}}<0$
(ii) $\frac{\partial b^{m *}}{\partial w_{1}^{m}}<0$

The optimal leave duration of a parent increases with an increase in the partner's income if and only if the change in the Pareto weight is stronger than the effect on the household's budget, i.e.

$$
\begin{aligned}
& \text { (iii) } \frac{\partial b^{f *}}{\partial w_{1}^{m}}>0 \Leftrightarrow \frac{\partial \mu_{1}}{\partial w_{1}^{m}}>\frac{1-\mu_{1}}{w_{1}^{m}+w_{1}^{f}+w^{p}\left(1+\frac{h_{0}^{m}+h_{0}^{f}}{T}\right)} \\
& \text { (iv) } \frac{\partial b^{m *}}{\partial w_{1}^{f}}>0 \Leftrightarrow-\frac{\partial \mu_{1}}{\partial w_{1}^{f}}>\frac{\mu_{1}}{w_{1}^{m}+w_{1}^{f}+w^{p}\left(1+\frac{h_{0}^{m}+h_{0}^{f}}{T}\right)}
\end{aligned}
$$


Proposition 3 The amount of professional childcare hired increases with total household income and is independent of distribution factors $z_{t}$ :

$$
\frac{\partial b^{p *}}{\partial\left(w_{1}^{m}+w_{1}^{f}\right)}>0 \quad \text { and } \quad \frac{\partial b^{p *}}{\partial z_{t}}=0
$$

Propositions 2 and 3 show that an increase in one partner's income has two effects. On the one hand, the level of public expenditures on professional childcare rises because of the increase in household income, which consequently reduces the total parental leave duration of the household (Proposition 3). On the other hand, it changes the allocation of power inside the household, and thus the intra-household allocation of parental childcare, shifting it in favor of the partner whose contribution to household income has increased. The cut-off levels, for a longer leave duration of one partner as a net response to an increase in the other partner's income are described in Proposition 2.

Whereas the previous propositions focus on changes in the composition of childcare sources, Proposition 4 describes how relative parental childcare shares compare depending on the intrahousehold distribution of power. When initial work experience from before period 1, symmetric preferences would imply an equal sharing of childcare responsibilities if Pareto weights are equal. However, if one partner has more power inside the household, e.g. due to potentially unobserved characteristics, social norms, etc., this partner turns out to bear the smaller share of parental leave.

Proposition 4 Consider a situation in which both partners have the same initial market work experience from before period 1, i.e. $h_{0}^{m}=h_{0}^{f}$. In this case the mother takes a longer leave period than the father whenever $\mu_{1}>1 / 2$.

Conditional on the level of household expenditures on professional childcare parents agreed upon, the Pareto weight $\mu_{1}$ determines how partners share the parental leave. If $\mu_{1}$ increases with relative income, and decreases with the age difference between the woman and the man, 
then women are likely to take longer leave periods than men, i.e. $b^{f *}>b^{m *}$, (i) if women contribute relatively less than men to total household income, and (ii) if women are younger than their spouses.

In the following section, we look at the empirical validity of these four proposition for German data.

\section{Legal Background and Data}

\subsection{The German Parental Benefit Legislation}

In 2007 a modified parental benefit legislation has been introduced in Germany. The new law is known as "Elterngeld". The benefit is now directed to the parent going on leave in order to take care of the child and not, as it has been the case until 2006, to the household. In addition, both parents have become eligible for the benefit independent of the individual and household income. No parent is excluded for passing an income threshold. The main eligibility conditions are residency in Germany, less than 30 hours of weekly working time, and legal guardian status for the child concerned. ${ }^{13}$

Under the new law, 67-100 percent of the average monthly net income over the previous 12 months before applying for parental benefit is paid as a tax-free benefit to a parent on leave. A minimum monthly benefit amount of EUR 300 is paid even on top of unemployment benefits. An upper bound of EUR 1,800 per month corresponds to a monthly net income of EUR 2,700. The amount of parental benefit is calculated from the individual income, so that two parents with different incomes receive different amounts. If a parent chooses to go on leave only part time, the monthly benefit is calculated based on the amount of net-income reduction. When a parent's net income is less than EUR 1,000, the percentage paid as benefit exceeds 67 percent, and reaches 100 percent for low incomes. The maximum total benefit duration per family is 14

\footnotetext{
${ }^{13}$ See Raute (2014) for more information on this reform and how it affected fertility rates.
} 
months, but each parent can at most go on paid leave for 12 months. Unpaid leave with job protection is possible thereafter for another 24 months. In order to exploit the full 14 months of paid leave, each parent has to stay at home for at least two months. ${ }^{14}$

Before 2007, the amount of parental benefit was not relative to net income. It also provided only one parent per birth with a fixed amount of EUR 300 per month, and only if the household's income was below a certain threshold. We do not observe whether only one or both parents went on leave. As a consequence, pre-2007 parental benefit data do not contain individual income information. In addition, there is no information available on the parent who did not apply for benefit.

\subsection{Data}

Our analysis uses survey data on young families provided by the Rhine-Westphalia Institute for Economic Research Essen (2008), hereafter RWI. The survey was conducted between May and June 2008 and 2009 on parents whose youngest child was born between January and April 2007. Mothers were interviewed and provided information on themselves and on their partners if applicable. The survey contains information on individual monthly net income, employment sector, educational attainment, and on the use of daycare facilities amongst a rich set of personal characteristics. The RWI survey also provides information on parents who did not receive benefit. It covers 4,177 randomly selected married and cohabiting hetero- and homosexual couples. ${ }^{15}$

Summary statistics for all variables used in the subsequent analysis are provided in Table 4. On average, mothers took ten months of parental leave while fathers took one. Fathers are also much more likely not to take any leave: $8 \%$ of mothers do not take parental leave while

\footnotetext{
${ }^{14}$ Single parents with exclusive custody for the child can go on paid leave for up to 14 months.

${ }^{15}$ See Appendix Appendix B for a comparison with administrative data. This second source of data contains less information on the socio-economic background of individuals than the RWI. In particular, reported paternity leave length in the RWI survey is higher on average than can be concluded from the administrative data. For the average maternity leave duration the two datasets give similar results.
} 
for fathers $76 \%$ of them who do not. Fathers are on average three years older than the mother and earn three times more. Table 5 also shows that leave duration is shorter for higher income groups. This picture is clear for mothers and fathers. This descriptive result is in line with Proposition 2.

\section{Empirical Results}

We first describe the econometric methods we use to study how parental leave is affected with individual characteristics and, in particular, distribution factors. Then, we provide empirical support to the theoretical assumption that households decisions concerning parental leave in Germany are efficient. We conclude with a discussion on Propositions 1 to 4 and how the data validates them.

\subsection{Econometric Method}

In order to investigate the intra-household allocation of parental leave, we regress maternity and paternity leave durations, and the amount of professional childcare use on a number of individual and household characteristics. Parental leave durations are non-negative integers with an upper bound at 12 in the considered cohort of cohabiting or married couples.

We follow Papke and Wooldridge (1996), who introduce a quasi-maximum likelihood estimator (QMLE henceforth) based on the logistic function in order to estimate fractional response models. This estimator is consistent and $\sqrt{N}$-asymptotically normal regardless of the distribution of the dependent variable, conditional on the regressors. The explained variable can be continuous or discrete, but is restricted to the unit interval $[0,1]$. Wooldridge (2002) points out that rescaling a variable that is restricted to an interval $[l, u]$, where $l<u$, using the

transformation $\left(h_{n}^{i}-l\right) /(u-l)=: \widetilde{h}_{n}^{i}$, does not affect the properties of their QMLE approach. Hereby, $i=\{f, m\}$ and $n=1,2, \ldots, N$ is a household index. For the subsequent logit QMLE 
regressions we rescale the leave durations $h_{n}^{i}$ setting $u=12$ and $l=0$. For comparability, also in the benchmark OLS estimations leave durations are rescaled.

$\mathbf{x}_{n}^{i}$ is the $1 \times K$ vector of explanatory variables from observation $i$ with one entry being equal to unity. Although in practice, $\mathbf{x}_{n}^{f}$ might be different from $\mathbf{x}_{n}^{m}$, we assume equality of the two for simplicity. Papke and Wooldridge (1996) assume that, for all $n$,

$$
\mathbb{E}\left[\widetilde{h}_{n}^{i} \mid \mathbf{x}_{n}\right]=G\left(\mathbf{x}_{n} \delta\right)
$$

The linear specification assumes $G\left(\mathbf{x}_{n} \delta\right)=\mathbf{x}_{n} \delta$ whereas in the non-linear fractional response model $G(\cdot)$ is chosen to be the logistic function $G\left(\mathbf{x}_{n} \delta\right)=\exp \left\{\mathbf{x}_{n} \delta\right\} /\left(1+\exp \left\{\mathbf{x}_{n} \delta\right\}\right)$ that satisfies $0<G(\cdot)<1$. QMLE is shown to be consistent as long as the conditional mean function (13) is

correctly specified. For the non-linear fractional response model, Papke and Wooldridge (1996) suggest to maximize the Bernoulli log-likelihood function

$$
l_{n}^{i}(\delta) \equiv \widetilde{h}_{n}^{i} \log \left[G\left(\mathbf{x}_{n} \delta\right)\right]+\left(1-\widetilde{h}_{n}^{i}\right) \log \left[1-G\left(\mathbf{x}_{n} \delta\right)\right]
$$

We begin our empirical analysis with the linear model as a benchmark, which we estimate by OLS with White (1980) heteroskedasticity-robust standard errors. We then estimate non-linear fractional response models based on the logistic function.

\subsection{Collective Rationality in Childcare Sharing}

Bourguignon, Browning, and Chiappori (2009) provide a characterization of testability in the collective framework when only cross-sectional data without price variation is available. They develop a necessary and sufficient test of the Pareto-efficiency hypothesis, where the presence of distribution factors is crucial. Their influence on behavior provides the only testable restrictions of the collective model. The collective setting encompasses all cooperative models that take Pareto optimality of allocations as an axiom.

Our study considers a version of the collective model where professional childcare use is con- 
sidered a public good that reduces total household leave time. Both parents try to minimize the time they stay absent of the labor market, because their incomes in period 2 negatively depend on their leave time (Equation (3)). Since there is no price variation in professional childcare in our data, we normalize $w^{p}$ to unity in the budget constraint (4). Each partner has preferences represented by (6). The arguments of the utility function affect preferences directly and are referred to as "preference factors" as in Bourguignon, Browning, and Chiappori (2009). Observable preference factors in the following estimations include parents' employment sector and educational attainment, regional location, citizenship, and the number and age of children.

The literature on collective models has paid considerable attention to relating the withinhousehold sharing of resources to distribution factors such as relative incomes and the age difference between spouses; see, for example, Browning et al. (1994) and Cherchye, De Rock, and Vermeulen (2011). We follow this approach and consider relative income and age difference (male minus female; corresponds to $a$ in the power function $\mu\left(w_{m}^{t} / w_{w}^{t}, a\right)$ as defined in section 2.2) as observable distribution factors. Unobservable preference and distribution factors go into the statistical error term $\varepsilon_{i n}$ and are assumed to be orthogonal to all observable characteristics.

Parental leave duration and professional childcare use are estimated as functions of the observable distribution factors, relative income of the man, and age difference $a_{n}$ (male minus female), while controlling for monthly household income $y_{n},{ }^{16}$ total parental leave duration $b_{n}^{\text {tot }}=b_{n}^{m}+b_{n}^{f}$, and further individual and household characteristics, denoted by vector $\mathbf{k}_{n}$, such as parents' employment sector, education, number of children in the household, twins, foreign mother, parents living in East Germany, and living in a big city. For all $i=\{m, f, p\}$ we then estimate:

$$
\mathbb{E}\left[\widetilde{h}_{n}^{i} \mid \mathbf{x}_{n}\right]=G\left(\alpha_{0}^{i}+\alpha_{1}^{i} \frac{w_{n}^{m}}{w_{n}^{f}}+\alpha_{2}^{i} a_{n}+\alpha_{3}^{i} y_{n}+\alpha_{4}^{i} b_{n}^{\text {tot }}+f^{i}\left(\mathbf{k}_{n}\right)\right) .
$$

We first test whether collective rationality is a good assumption when looking at parental leave decisions within households in Germany. We then provide a series of robustness checks.

\footnotetext{
${ }^{16}$ As we only observe two sources of income, we have $y_{n}=w_{n}^{m}+w_{n}^{f}$.
} 


\subsubsection{Distribution Factors and Pareto Optimality}

The first testable implication comes from Proposition 1 in Bourguignon, Browning, and Chiappori (2009, p. 509) and is a generalization of the income-pooling hypothesis that has been tested and rejected by Browning et al. (1994) and Lundberg, Pollak, and Wales (1997) among others. It comes from the implication of the collective model that, without price variation, a model of collective decision making is observationally equivalent to a unitary setting as long as the weights of the individual utilities in the household utility function do not depend on distribution factors. On cross-sectional data without price variation, testing for collective rationality therefore requires the presence of distribution factors. ${ }^{17}$ The demands for leave time are compatible with unitary rationality if and only if

$$
\alpha_{1}^{i}=0 \text { and } \alpha_{2}^{i}=0, \quad \forall i=\{m, f, p\}
$$

This means that in the unitary framework, the impact of distribution factors on parental leave durations and professional childcare use are zero once we control for total household income and preference factors.

Table 6 shows that the impact of the distribution factors on maternity and paternity leave duration is individually and jointly different from zero in each of the two estimations. If leave time was split between parents based on unitary rationality neither relative income nor age differences should affect the sharing rule once we control for the level of household income. Table 6 therefore provides first evidence for collective rationality in parental leave sharing.

The decision to hire professional childcare, however, does not depend on distribution factors, but only on total household income as can be seen in Table 7. This finding is in line with the assumption of considering professional childcare as a public good within households. It also gives empirical support to Proposition 3 and confirms the expression we obtained for $b^{p *}$ in Equation (11), where only joint household income but no distribution factors enter.

\footnotetext{
${ }^{17}$ See Bourguignon, Browning, and Chiappori (2009, p. 509) for further discussion.
} 
The central assumption for the allocation of private goods in collective models is that the intrahousehold decision process leads to a Pareto-efficient outcome. This is what Bourguignon, Browning, and Chiappori (2009) refer to as collective rationality. The main testable prediction based on variation in distribution factors follows from Proposition 2 in Bourguignon, Browning, and Chiappori (2009, p. 510), which has become know as the proportionality condition. The authors show that this condition is necessary and sufficient for collective demands to be compatible with collective rationality in cross-sectional data without price variation.

The test is based on the idea that, by definition, distribution factors do not affect the Pareto set. They influence the intra-household allocation of goods only through their one-dimensional impact on Pareto weights, which in turn determines the final location on the Pareto frontier. In order to test whether the impact of distribution factors on the final allocation is indeed one-dimensional, at least two distribution factors need to be present.

The proportionality condition implies that the effect of distribution factors on the optimal leave duration is proportional to the influence of the distribution factors on the intra-household distribution of power function, i.e.

$$
\frac{\partial \mu(\mathbf{z}) / \partial \frac{w_{n}^{m}}{w_{n}^{n}}}{\partial \mu(\mathbf{z}) / \partial a_{n}}=\frac{\alpha_{1}^{i}}{\alpha_{2}^{i}} \quad \forall i=\{m, f\} .
$$

Since the proportionality condition holds for both, maternity and paternity leave durations, the ratio of partial derivatives needs to be equal for both partners:

$$
\frac{\alpha_{1}^{m}}{\alpha_{2}^{m}}-\frac{\alpha_{1}^{f}}{\alpha_{2}^{f}}=0 .
$$

The last line in Table 6 shows that a $95 \%$ bootstrap confidence interval of the left-hand side of equation (15) contains the zero. Therefore, the proportionality hypothesis cannot be rejected. In addition, the ratios are negative in both models. These results provide further evidence for collective rationality in parental leave sharing. In line with Proposition 1, the parent with a higher relative income has more intra-household power which puts him or her in the position 
to shift a bigger leave time share to the partner. For couples with a larger age difference, leave sharing is shifted towards the younger partner.

\subsubsection{Robustness Checks and Limitations}

Testing the impact of distribution factors on parental leave durations and the proportionality condition requires the joint estimation of the system of parental leave equations which allows for disturbance term correlations across equations. We then need to test linear and nonlinear crossequation restrictions over the parameter estimates of the distribution factors. Unfortunately, Wald tests tend to overreject the null hypothesis in system OLS and seemingly unrelated regression models. In addition, nonlinear Wald test statistics are invariant to reformulations of the null. We follow Bobonis (2009) for both issues. In a first robustness check, we present $p$-values from the bootstrap percentile interval of the test statistic when testing across models (Table 8), which has been shown to significantly reduce the overrejection bias in this setting. Second, we assess the robustness of our inferences by constructing linear Wald tests as described below. Another potential concern is that families in which there is already one older child, specialization is already in place. Our last robustness check restricts the sample to families who had their first child over the period in which the survey was conducted.

\section{Robustness Check 1: Log Incomes and Income Effects}

By considering log incomes, we can test for Pareto optimality in leave sharing in an alternative way. For all $i=\{m, f\}$, we estimate:

$$
\mathbb{E}\left[\widetilde{h}_{n}^{i} \mid \mathbf{x}_{n}\right]=G\left(\beta_{0}^{i}+\beta_{1}^{i} \ln \left(w_{n}^{m}\right)+\beta_{2}^{i} \ln \left(w_{n}^{f}\right)+\beta_{3}^{i} a_{n}+\beta_{4}^{i} b_{\text {totn }}+f^{i}\left(\mathbf{k}_{n}\right)\right)
$$

If we assume that only relative income matters for the leave time sharing rule, then we can check the proportionality condition by testing whether the sum of the log income coefficients equals zero;

$$
\beta_{1}^{i}+\beta_{2}^{i}=0 \quad \forall i=\{m, f\}
$$


This hypothesis cannot be rejected, neither individually nor jointly across models. Therefore, Table 8 provides further pieces of evidence for Pareto optimality in parental leave sharing as, again, the Wald tests cannot reject the proportionality hypothesis.

In addition, we present estimates of Tobit models with a lower censoring at 0 and an upper censoring at 12 months of paid leave. The magnitudes of the income effects are larger in absolute terms than in the fractional logit regressions as the Tobit models focus on interior solutions. ${ }^{18}$ Families who do not opt for a corner solution, i.e. where each partner takes a strictly positive leave time, are likely to react stronger to a change in relative incomes as compared to partners opting for a corner solution. This is because the decision to temporarily drop out of the labor market has been already taken by both parents.

\section{Robustness Check 2: z-Conditional Demands}

Further testable implications come from an alternative demand system that is consistent with collective rationality. It follows from the effect of distribution factors on the intra-household allocation being one-dimensional, which is implied by the proportionality condition. Independent of the number of distribution factors, they can influence the parental leave allocation among parents only through a single, real-valued function $\mu(\mathbf{z})$. The demand for one good can therefore be expressed as a function of the demand for another good.

Bourguignon, Browning, and Chiappori (2009) introduce $z$-conditional demands which are useful to resolve, e.g., the empirical difficulty of nonlinear Wald test statistics being noninvariant to reformulations of the null hypothesis. We follow Bobonis (2009) and construct linear Wald tests based on parametric versions of the $z$-conditional demand functions in order to assess the robustness of our previous results to reformulations of the null hypotheses.

The idea of $z$-conditional demands is demonstrated in the following for $G(\cdot)$ being the logistic function. Under the assumption that relative income $w_{n}^{m} / w_{n}^{f}$ has a strictly monotone influence

\footnotetext{
${ }^{18}$ Note that the dependent variables in columns 2 and 4 of Table 8 are not rescaled. Therefore, coefficients do not need to be multiplied by 12 as in the other tables.
} 
on optimal leave sharing, we rewrite (14) as

$$
\frac{w_{n}^{m}}{w_{n}^{f}}=\frac{1}{\alpha_{1}^{i}} \ln \left(\frac{\widetilde{h}_{n}^{i}}{1-\widetilde{h}_{n}^{i}}\right)-\frac{\alpha_{0}^{i}}{\alpha_{1}^{i}}-\frac{\alpha_{2}^{i}}{\alpha_{1}^{i}} a_{n}-\frac{\alpha_{3}^{i}}{\alpha_{1}^{i}} b_{n}^{\text {tot }}-\frac{1}{\alpha_{1}^{i}} f^{i}\left(\mathbf{k}_{n}\right)-\frac{1}{\alpha_{1}^{i}} \varepsilon_{n}^{i} \quad \forall i=\{m, f\} .
$$

As total household leave duration is simply the sum of maternity and paternity leave time, we can replace $b_{n}^{\text {tot }}$ by $b_{n}^{i}+12 \widetilde{h}_{n}^{j}$, where $j=\{m, f\}$ and $j \neq i$ represents the partner. We can substitute the above equation into (14) to obtain ${ }^{19}$

$$
\begin{array}{r}
\mathbb{E}\left[\widetilde{h} j_{n} \mid \mathbf{x}_{n}\right]=G\left(\frac { 1 } { \alpha _ { 1 } ^ { i } ( 1 - 1 2 \alpha _ { 3 } ^ { j } ) + 1 2 \alpha _ { 3 } ^ { i } \alpha _ { 1 } ^ { j } } \left(\left(\alpha_{1}^{i} \alpha_{0}^{j}-\alpha_{0}^{i} \alpha_{1}^{j}\right)+\left(\alpha_{1}^{i} \alpha_{2}^{j}-\alpha_{2}^{i} \alpha_{1}^{j}\right) a_{n}\right.\right. \\
\left.\left.+\left(\alpha_{1}^{i} \alpha_{3}^{j}-\alpha_{3}^{i} \alpha_{1}^{j}\right) b_{n}^{i}+\alpha_{1}^{j} \ln \left(\frac{\widetilde{h}_{n}^{i}}{1-\widetilde{h}_{n}^{i}}\right)+\left(\alpha_{1}^{i} f^{j}\left(\mathbf{a}_{n}\right)-\alpha_{1}^{j} f^{i}\left(\mathbf{k}_{n}\right)\right)\right)\right) .
\end{array}
$$

Benchmark OLS and fractional logit regression results are provided in Table 9. As expected we find that the mother's contribution to total household income has no significant impact on either maternity or paternity leave duration anymore once we control for the partner's leave duration. This must be true if the collective model is correct as the father's contribution to household income as one distribution factor already absorbs the one-dimensional effect of all distribution factors together on parental leave sharing.

\section{Robustness Check 3: First Births and Tobit Estimations}

A concern might be that in families, who already had children before the most recent one, parents might have specialized in different activities. Mothers might have provided the larger share of childcare already for the older children and are therefore relatively more productive in

\footnotetext{
${ }^{19}$ Note that if $G(\cdot)$ is linear total household leave duration becomes redundant once we control for the partner's leave duration and

$$
\begin{aligned}
\mathbb{E}\left[\tilde{h}_{j n} \mid \mathbf{x}_{n}\right]=\frac{1}{\alpha_{1}^{i}\left(1-12 \alpha_{3}^{j}\right)+12 \alpha_{3}^{i} \alpha_{1}^{j}}( & \left(\alpha_{1}^{i} \alpha_{0}^{j}-\alpha_{0}^{i} \alpha_{1}^{j}\right)+\left(\alpha_{1}^{i} \alpha_{2}^{j}-\alpha_{2}^{i} \alpha_{1}^{j}\right) a_{n} \\
& \left.+\left(\alpha_{1}^{i} \alpha_{3}^{j}-\alpha_{3}^{i} \alpha_{1}^{j}\right) b_{n}^{i}+\left(\alpha_{1}^{i} f^{j}\left(\mathbf{a}_{n}\right)-\alpha_{1}^{j} f^{i}\left(\mathbf{k}_{n}\right)\right)+\left(\alpha_{1}^{i} \varepsilon_{n}^{j}-\alpha_{1}^{j} \varepsilon_{n}^{i}\right)\right) .
\end{aligned}
$$
}


childcare provision than fathers. In this sense the lower market income of women reflects their specialization in household production and not their lower intra-household power.

In order to address this concern, in Table 10, we restrict our sample to families without any older children, which reduces the sample to about $57 \%$ of the full sample. We redo the fractional logit estimations of Table 6 and find similar results. As in Table 8 we compare the estimates of our previous analysis with the results of Tobit model estimations and can completely confirm our findings from before.

\section{Concerns and Limitations}

The variation in relative income and age difference between households could be correlated with unobservable characteristics of couples like varying separation probabilities. In this case couples with a lower risk of divorce may have different preferences for childcare sharing than partners with a high risk of separation. The considered distribution factors would then have an indirect

effect on the sharing rule through the effect on divorce probabilities. However, Bobonis (2009) points out that tests of the proportionality condition are not invalidated by this possibility since the ratio of the direct and indirect effects of changes in relative income and/or age difference on Pareto weights does not involve anything specific to either maternity or paternity leave durations. Effects of changes in those factors on leave durations are again equally proportional to the distribution factors' influence on the intra-household power distribution.

Another concern addresses unobserved heterogeneity in distribution factor effects on individual leave durations, which involves the possibility of differences in estimated coefficients stemming from heterogeneity in individuals' preferences rather than from differences in individuals' intra-household power. Changes in the age difference might, e.g., affect total household leave durations mainly in the lower range of the distribution between 0 and 12 months if age difference mainly affects maternity leave duration in a way that in couples with a small age difference women rather take paid leave for less than the maximum duration. Men's relative income, on the other hand, might affect more the upper range of the leave distribution between 12 and 
14 months because relatively better earning men, i.e. relative to their spouses, mainly decide whether to participate in parental leave at all and are unlikely to take more than the minimum requirement of two months.

The main consequence would be that Pareto optimality tests, which rely on condition (15), may consider significant differences between the ratios of distribution factor coefficients in the demand for different goods as evidence against the predictions of the collective model. Rejections of the proportionality condition could then be caused by heterogeneity in household demand functions. As we cannot reject Pareto efficiency in parental leave sharing, this concern does not seem to be harmful in our application.

Finally, if individuals' preferences for leisure are not separable from those for leave time or childcare, respectively, the estimated income effects may suffer from an omitted variable bias. We therefore assume that conditioning on employment status before birth, employment sector, and additional socioeconomic and demographic variables, preferences for leisure are separable from those for childcare. A related limitation of relative income as a distribution factor is that labor incomes may be endogenous to households' childcare allocation decisions. Due to a lack of observed non-labor income or exogenous variation in incomes, we need to focus on correlations of relative incomes with household demands.

\subsection{Empirical Intra-Household Allocation of Parental Leave}

This section concludes with a more detailed discussion on the empirical support to the Propositions 1 to 4 derived from the theory.

\section{Proposition 1}

Contrary to what would be the outcome of an unitary framework of family decision, Proposition 1 states that distribution factors matter for parental leave sharing between spouses. Examples of distribution factors in the absence of price variation that have been suggested 
in the literature, include relative incomes, age difference, relative physical attractiveness, and local sex ratio. In the context of leave sharing, custody allocation after divorce and alimony transfers from the custody to the non-custody parent are also examples of distribution factors. Due to a lack of substantial variation in the other potential distribution factors between the 16 German states, ${ }^{20}$ for the empirical analysis we need to focus on relative income and age difference changes while controlling for the level of household income. A unitary model would predict that only the level and not the sources of household income matter.

As already argued, Table 6 provides evidence for collective rationality in parental leave sharing by confirming the impact of distribution factors on individual leave durations. A higher relative income of the father and/or a larger age difference are correlated with longer maternity leave and shorter paternity leave. The level of household income does not have a significant impact on parental leave durations, once we control for relative income. This finding provides evidence for the wealth effect on paid leave durations being weaker than the bargaining effect.

\section{Proposition 2}

Proposition 2 predicts that each spouse's leave share is decreasing in own income. Empirical support for this prediction is presented in Table 8. The magnitudes of the Tobit parameter estimates from Table 10 tell us that doubling the mother's income leads to a 1.4 months decrease of her own parental benefit duration. For fathers the corresponding coefficient from the last column of Table 8 is a little bit larger in absolute terms: it corresponds to a month and a half decrease.

Additionally, doubling the mother's earnings involves an increase in the father's leave time of about four fifth of a month. If the father's income is doubled, the coefficient is more than twice as big, i.e. mothers go on leave for 1.6 months longer. The magnitude of the coefficients might even be expected to become larger in absolute terms in the future if we consider that the most recent data available are from the first third of 2007 - the four months after the new parental

\footnotetext{
${ }^{20}$ Unfortunately, we do not observe smaller geographical regions than states.
} 
benefit legislation has been introduced in Germany.

Tables 1 and 2 demonstrate a strong asymmetry between maternity and paternity leave durations on an aggregate level. Table 1 tells us that, based on the Parental Benefit Statistic, for 95.3 percent of the children born in 2007 the mother went on leave for at least one month. This number needs to be compared to only 13.3 percent of fathers who took at least one month off. Table 2 then shows that fathers take only 5.3 percent of the total leave duration. However, if we look at the development of fathers' participation rate in parental leave in Scandinavian countries, who introduced generous parental leave legislations much earlier, paternity leave durations in Germany can be expected to increase in the future.

\section{Proposition 3}

Proposition 3 predicts that professional childcare use increases with household income, but is independent of distribution factors. From the RWI survey data, we observe that $30.7 \%$ of parents with a monthly household net income below EUR 2,000 plan to hire professional childcare. This percentage rises with income until it reaches $55.4 \%$ for parents with a household income of more than EUR 5,000. Marginal effects from logit QMLE in Table 7 suggest that only household income and not relative income or age difference matter for the decision to hire professional childcare. In particular, a family is roughly $2.4 \%$ more likely to hire professional childcare if monthly household net income exceeds the average income of households by EUR $1,000 \cdot{ }^{21}$

\section{Proposition 4}

Proposition 4 states that the mother's leave share is relatively larger if the father's Pareto weight is relatively stronger. This theoretical result is difficult to bring to the data, as the exact functional form of the power function is unknown. A multiplicity of factors are likely to determine the exact intra-household "distribution of power" out of which we observe substantial

\footnotetext{
${ }^{21} \mathrm{As}$ the dependent variable is a dummy, logit QMLE simplifies to a usual logit estimation. We calculate marginal effects with all variables at means. Qualitative results for different covariate values are similar and available from the authors upon request.
} 
variation only in two distribution factors (relative income and age difference).

We still provide suggestive empirical evidence for women to be represented in childcare relatively stronger than their partner in couples where the woman's Pareto weight is relatively weaker. We construct a dummy variable which equals one if the woman takes more leave time than the man. A second dummy equals one if the man's contribution to household income is bigger than the woman's. Then, families in which the latter dummy variable equals one are 5.1 percent more likely that the woman takes relatively more leave time than families where the man's relative income is less than $1 .^{22}$

However, while in $65 \%$ of the observed households from the RWI survey the man's relative income is larger than 1 and in $73 \%$ the man is older that the woman, in more than 89 percent of households the woman's relative leave time is larger than 1. This means that, as the effect of all distribution factors on the intra-household allocation of leave time is one-dimensional, we are able to infer the effect of changes in the observed distribution factors on relative leave times to happen through changes in relative Pareto weights. Still, we cannot credibly predict the exact magnitude of the man's and the woman's Pareto weight in a given household without knowing the exact functional form and without observing all arguments of the power function.

\section{Conclusion}

This paper aims to gain insight into the process that determines how parental childcare sharing is influenced by the intra-household distribution of power. Lengthy parental leave periods involve long-term income and career penalties even in countries with a generous paid leave legislation. Therefore, both parents value labor market work as an input to their human capital that positively impacts their individual incomes later in life - which translates into a higher level of future private consumption.

\footnotetext{
${ }^{22}$ The $t$ statistic of the marginal effect is 4.2 when regressing the leave-time dummy on the relative-income dummy in a logit regression while using the same remaining controls as in Table 6.
} 
We introduce parental leave sharing in a collective model of household behavior with public consumption. The model's restrictions are tested on survey data of young German families. The collective model is identified through the existence of distribution factors that affect household decisions even though they do not impact preferences nor budgets directly.

Although all decisions happen simultaneously, the leave allocation can be imagined to happen in a two-stage process: Parents first agree on public expenditures on professional childcare use. Then, and conditional on the amount of public good consumption, partners choose the time they spend on childcare as well as their levels of private consumption. Each partner's leave time is the shorter and private consumption is the higher, the stronger a partner's power initially is. Market work is valued as an investment in human capital which increases expected future income. A higher personal income c.p. increases the household income and the relative income. It therefore translates into a higher consumption level for the household and a larger personal consumption share through a stronger Pareto weight. Households face one trade-off concerning the allocation of childcare time conflicting with work time between partners, and a second trade-off related to an intertemporal private consumption allocation between the nearer and the farther future by choosing the amount of professional childcare to hire.

To summarize, the childcare allocation is sensitive to relative incomes and age differences. It is more equal in households where the woman contributes relatively more to household income and where the woman is relatively older. In addition, parental leave time and the involved income and career penalties are allocated strongly towards women. This is correlated to men usually contributing relatively more to household income and being older than their partner. Possibly, the economically weak outside option for women as a single mother even boosts the inequality in leave time sharing. ${ }^{23}$

\footnotetext{
${ }^{23}$ Alimony transfers by the father help to reduce the inequality after divorce, but DiPrete and McManus (2000) and Bartfeld (2000) among others find that the economic situation of custodial-mother families is still dramatically worse than the economic situation of fathers after separation.
} 


\section{References}

Amilon, Anna. 2007. "On the sharing of temporary parental leave: the case of Sweden." Review of Economics of the Household 5 (4): 385-404.

Apps, Patricia, and Ray Rees. 1988. "Taxation and the Household." Journal of Public Economics 35 (3): 355-369.

Bartfeld, Judi. 2000. "Child support and the postdivorce economic well-being of mothers, fathers, and children." Demography 37 (2): 203-213.

Basu, Kaushik. 2006. "Gender and Say: A Model of Household Behaviour With Endogenously Determined Balance of Power." Economic Journal 116 (511): 558-580.

Blundell, Richard, Pierre Chiappori, and Costas Meghir. 2005. "Collective labor supply with children." J Polit Econ 113 (6): 1277-1306.

Bobonis, Gustavo. 2009. "Is the allocation of resources within the household efficient? New evidence from a randomized experiment." Journal of Political Economy 117:453-503.

Bourguignon, François, Martin Browning, and Pierre Chiappori. 2009. "Efficient intrahousehold allocations and distribution factors: implications and identification." Review of Economic Studies 76:503-528.

Browning, Martin, François Bourguignon, Pierre Chiappori, and Valerie Lechene. 1994. "Income and outcomes: A structural model of intrahousehold allocation." Journal of Political Economy 102 (6): 1067-1096.

Browning, Martin, and Pierre Chiappori. 1998. "Efficient intra-household allocations: A general characterization and empirical tests." Econometrica 66:1241-1278.

Browning, Martin, Pierre-André Chiappori, and Yoram Weiss. 2014. Economics of the Family. Cambridge University Press.

Cherchye, Laurens, Bram De Rock, and Frederic Vermeulen. 2011. "The revealed preference approach to collective consumption behaviour: Testing and sharing rule recovery." Review of Economic Studies 78 (1): 176. 
Chiappori, Pierre. 1988. "Rational household labor supply." Econometrica 56:63-90.

Chiappori, Pierre, and Ivar Ekeland. 2006. "The microeconomics of group behavior: general characterization." Journal of Economic Theory 130:1-26.

Chiappori, Pierre, Bernard Fortin, and Guy Lacroix. 2002. "Marriage market, divorce legislation, and household labor supply." Journal of Political Economy 110:37-72.

Chiappori, Pierre, and Yoram Weiss. 2007. "Divorce, remarriage, and child support." Journal of Labor Economics 25:37-74.

Corcoran, Mary, and Greg Duncan. 1979. "Work history, labor force attachment, and earnings differences between the races and sexes." Journal of Human Resources 14:3-20.

DiPrete, Thomas, and Patricia McManus. 2000. "Family change, employment transitions, and the welfare state: Household income dynamics in the United States and Germany." American Sociological Review 65:343-370.

Duflo, Esther, and Christopher Udry. 2004, May. "Intrahousehold Resource Allocation in Cote d'Ivoire: Social Norms, Separate Accounts and Consumption Choices." Working paper 10498, National Bureau of Economic Research.

Dustmann, Christian, and Uta Schönberg. 2012. "Expansions in maternity leave coverage and children's long-term outcomes." American Economic Journal: Applied Economics 4 (3): $190-224$.

Ekberg, John, Rickard Eriksson, and Guido Friebel. 2013. "Parental leave?A policy evaluation of the Swedish "Daddy-Month" reform." Journal of Public Economics 97 (C): 131-143.

Erosa, Andrés, Luisa Fuster, and Diego Restuccia. 2002. "Fertility decisions and gender differences in labor turnover, employment, and wages." Review of Economic Dynamics $5: 856-891$.

Federal Statistical Office of Germany. 2008. "Öffentliche Sozialleistungen, Statistik zum Elterngeld, Elterngeld für Geburten 2007, Bezüge von Januar 2007 bis Dezember 2007." Federal Statistical Office, Wiesbaden. 
Gobbi, Paula. 2014. "Childcare and Commitment within Households." Working Paper (https://drive.google.com/file/d/OB-XFw3XP1TbRXzZ3LVJIOEVycGM).

Iyigun, Murat, and Randall P. Walsh. 2007a. "Building the family nest: Premarital investments, marriage markets, and spousal allocations." Review of Economic Studies 74 (2): $507-535$.

—. 2007b. "Endogenous gender power, household labor supply and the demographic transition." Journal of Development Economics 82 (1): 138-155.

Konrad, Kai A., and Kjell Erik Lommerud. 1995. "Family Policy with Non-cooperative Families." Scandinavian Journal of Economics 97 (4): 581-601.

- 2000. "The bargaining family revisited." Canadian Journal of Economics/Revue canadienne d'économique 33 (2): 471-487.

Lundberg, Shelly, Robert Pollak, and Terence Wales. 1997. "Do husbands and wives pool their resources? Evidence from the United Kingdom child benefit." Journal of Human Resources 32:463-480.

Mazzocco, Maurizio, Claudia Ruiz, and Shintaro Yamaguchi. 2014. "Labor Supply and Household Dynamics." The American Economic Review 104 (5): 354-359.

Mincer, Jacob, and Solomon Polachek. 1974. "Family investments in human capital: Earnings of women." Journal of Political Economy 82:76-108.

Papke, Leslie, and Jeffrey Wooldridge. 1996. "Econometric methods for fractional response variables with an application to 401 (k) plan participation rates." Journal of Applied Econometrics 11:619-632.

Raute, Anna. 2014. "Do financial incentives affect fertility - Evidence from a reform in maternity leave benefits." Unpublished.

Rhine-Westphalia Institute for Economic Research Essen. 2008. "Evaluation des Gesetzes zum Elterngeld und zur Elternzeit, Endbericht." Projekt für das Bundesministerium für Familie, Senioren, Frauen und Jugend. RWI Projektberichte, Essen. 
Ruhm, Christopher. 1998. "The economic consequences of parental leave mandates: Lessons from Europe." Quarterly Journal of Economics 113:285-317.

Schönberg, Uta, and Johannes Ludsteck. 2014. "Expansions in maternity leave coverage and mothers' labor market outcomes after childbirth." Journal of Labor Economics 32 (3): 469-505.

White, Halbert. 1980. "A heteroskedasticity-consistent covariance matrix estimator and a direct test for heteroskedasticity." Econometrica 48 (4): 817-838.

Wooldridge, Jeffrey. 2002. Econometric analysis of cross section and panel data. MIT press. 


\section{Appendix A Mathematical Appendix}

\section{Appendix A.1 Solution of the Model}

\section{The Maximization from Section 2.2}

Each spouse has to allocate his or her time in period 1 between market work and childcare. The time in period 2 is allocated to market work. The problem has therefore five endogenous variables: $h_{1}^{m}, h_{1}^{f}, b^{m}, b^{f}$ and $b^{p}$.

From the budget constraint (4), $c_{2}^{m}$ from equation (8) and the time constraint (2), the functions $U_{t}^{m}$ and $U_{t}^{f}$ can now be written as

$$
\begin{aligned}
U_{1}^{m} & =\ln \left(T\left(w_{1}^{m}+w_{1}^{f}\right)-c_{1}^{f}-b^{p} w^{p}\right) \\
U_{2}^{m} & =\ln \left(\left(b^{f}+b^{p}+h_{0}^{m}\right) w_{1}^{m}\right) \\
U_{1}^{f} & =\ln \left(c_{1}^{f}\right) \\
U_{2}^{f} & =\ln \left(\left(T-b^{f}+h_{0}^{f}\right) w_{1}^{f}\right) .
\end{aligned}
$$

Replacing these expressions into the expression of $\mathbb{L}$ given in (9), we can then solve for the variables $b^{f}, c_{1}^{f}, b^{p}$ with only the non-negativity conditions as constraints. We obtain the following FOCs:

$$
\begin{aligned}
\hat{\mathbb{L}}^{(1,0,0)} \equiv & =0 \\
\hat{\mathbb{L}}^{(0,1,0)} \equiv{\frac{\mu_{1}}{b_{w}^{1}+b_{p}+h_{0}^{m}}-\frac{1-\mu_{1}}{T^{1}-b_{w}^{1}+h_{w}^{0}}}_{\frac{-\mu_{1}}{T^{1}\left(w_{m}^{1}+w_{w}^{1}\right)-c_{w}^{1}-b_{p} w_{p}}+\frac{1-\mu_{1}}{c_{w}^{1}}} & =0 \\
\hat{\mathbb{L}}^{(0,0,1)} \equiv \mu_{1}\left(-\frac{w_{p}}{T^{1}\left(w_{m}^{1}+w_{w}^{1}\right)-c_{w}^{1}-b_{p} w_{p}}+\frac{1}{b_{w}^{1}+b_{p}+h_{0}^{m}}\right) & =0 .
\end{aligned}
$$

Where $\hat{\mathbb{L}}^{(1,0,0)}, \hat{\mathbb{L}}^{(0,1,0)}$ and $\hat{\mathbb{L}}^{(0,0,1)}$ are the derivatives of $\mathbb{L}$ with respect to $b^{f}, c_{1}^{f}$ and $b^{p}$ respec- 
tively. We can rewrite the FOCs as

$$
\begin{aligned}
\mu_{1}\left(T^{1}-b_{w}^{1}+h_{w}^{0}\right) & =\left(1-\mu_{1}\right)\left(b_{w}^{1}+b_{p}+h_{0}^{m}\right) \\
w_{p}\left(b_{w}^{1}+b_{p}+h_{0}^{m}\right) & =T^{1}\left(w_{m}^{1}+w_{w}^{1}\right)-c_{w}^{1}-b_{p} w_{p} \\
\mu_{1}\left(c_{w}^{1}\right) & =\left(1-\mu_{1}\right)\left(T^{1}\left(w_{m}^{1}+w_{w}^{1}\right)-c_{w}^{1}-b_{p} w_{p}\right)
\end{aligned}
$$

which is a linear equation system in three variables. The solution of this system is indicated in equations (10), (11) and (12).

\section{Determining the Extreme Value}

Following the procedure in the description above yields an extreme value, of which we have to determine whether it is a maximum or minimum. Lets assume for the moment that the nonnegativity constraints are non-binding, (see the part "The Non-negativity Constraints" below). The Hessian of $\hat{\mathbb{L}}$ is given by

$$
\mathbb{H}=\left[\begin{array}{ccc}
\hat{\mathbb{L}}^{(2,0,0)} & \hat{\mathbb{L}}^{(1,1,0)} & \hat{\mathbb{L}}^{(1,0,1)} \\
\hat{\mathbb{L}}^{(1,1,0)} & \hat{\mathbb{L}}^{(0,2,0)} & \hat{\mathbb{L}}^{(0,1,1)} \\
\hat{\mathbb{L}}^{(1,0,1)} & \hat{\mathbb{L}}^{(0,1,1)} & \hat{\mathbb{L}}^{(0,0,2)}
\end{array}\right]
$$

with

$$
\begin{aligned}
\hat{\mathbb{L}}^{(2,0,0)}\left(b^{f *}, c_{1}^{f *}, b^{p *}\right) & =-\frac{\mu_{1}}{\left(b^{f *}+b^{p *}+h_{0}^{m}\right)^{2}}-\frac{1-\mu_{1}}{\left(T-b^{f *}+h_{0}^{f}\right)^{2}}<0 \\
\hat{\mathbb{L}}^{(0,2,0)}\left(b^{f *}, c_{1}^{f *}, b^{p *}\right) & =-\frac{\mu_{1}}{\left(\left(w_{1}^{m}+w_{1}^{f}\right) T-w^{p} b^{p *}-c_{1}^{f *}\right)^{2}}-\frac{1-\mu_{1}}{\left(c_{1}^{f *}\right)^{2}}<0 \\
\hat{\mathbb{L}}^{(0,0,2)}\left(b^{f *}, c_{1}^{f *}, b^{p *}\right) & =-\mu_{1}\left(\frac{1}{\left(b^{f *}+b^{p *}+h_{0}^{m}\right)^{2}}+\left(\frac{w^{p}}{\left(w_{1}^{m}+w_{1}^{f}\right) T-w^{p} b^{p *}-c_{1}^{f *}}\right)^{2}\right)<0 \\
\hat{\mathbb{L}}^{(1,1,0)}\left(b^{f *}, c_{1}^{f *}, b^{p *}\right) & =0 \\
\hat{\mathbb{L}}^{(1,0,1)}\left(b^{f *}, c_{1}^{f *}, b^{p *}\right) & =-\frac{\mu_{1}}{\left(b^{f *}+b^{p *}+h_{0}^{m}\right)^{2}}<0 \\
\hat{\mathbb{L}}^{(0,1,1)}\left(b^{f *}, c_{1}^{f *}, b^{p *}\right) & =-\frac{\mu_{1} w^{p}}{\left(\left(w_{1}^{m}+w_{1}^{f}\right) T-w^{p} b^{p *}-c_{1}^{f *}\right)^{2}}<0 .
\end{aligned}
$$


The first minor is negative, the second is $\left|\mathbb{H}_{2}\right| \equiv \hat{\mathbb{L}}^{(2,0,0)} \hat{\mathbb{L}}^{(0,2,0)}>0$. The determinant of the Hessian at the maximum is

$$
\begin{aligned}
\left|\mathbb{H}_{3}\left(b^{f *}, c_{1}^{f *}, b^{p *}\right)\right| \equiv \hat{\mathbb{L}}^{(2,0,0)}\left(b^{f *}, c_{1}^{f *}, b^{p *}\right) \hat{\mathbb{L}}^{(0,2,0)}\left(b^{f *}, c_{1}^{f *}, b^{p *}\right) \hat{\mathbb{L}}^{(0,0,2)}\left(b^{f *}, c_{1}^{f *}, b^{p *}\right) \\
-\hat{\mathbb{L}}^{(2,0,0)}\left(\hat{\mathbb{L}}^{(0,1,1)}\left(b^{f *}, c_{1}^{f *}, b^{p *}\right)\right)^{2}-\hat{\mathbb{L}}^{(0,0,2)}\left(b^{f *}, c_{1}^{f *}, b^{p *}\right)\left(\hat{\mathbb{L}}^{(1,0,1)}\left(b^{f *}, c_{1}^{f *}, b^{p *}\right)\right)^{2}<0 .
\end{aligned}
$$

Therefore, the Hessian is negative definite at $\left(b^{f *}, c_{1}^{f *}, b^{p *}\right)$ and $\hat{\mathbb{L}}\left(b^{f *}, c_{1}^{f *}, b^{p *}\right)$ is a maximum.

\section{The Non-negativity Constraints}

When maximizing function (9), we consider only the case where the non-negativity constraints are non-binding. In order for this to be meaningful, we have to show that there exists a range of parameters, for which the non-negativity constraints are indeed non-binding.

From equation (10) we see that if the Pareto weight of one spouse equals zero, this leads to an excessive leave duration for the other spouse, i.e. $\mu_{1}=1 \Rightarrow b^{f *} \geq T$. The interpretation is that if the utility of one spouse has no importance, then this partner would be overly exploited in favor of the other. The non-negativity constraints therefore only hold for an intermediate range of Pareto weights $\underline{\mu}$ to $\bar{\mu}$ with $0<\underline{\mu}<\bar{\mu}<1$. Outside of this range, a corner solution with $b^{m}=0$ or $b^{f}=0$ maximizes the household's utility. In the following, we show that all constraints can hold at the same time, so that we are not in a degenerate case.

The non-negativity constraints for the duration of maternity and paternity leaves can be respectively written:

$$
\begin{array}{ccc} 
& b^{f *} & \geq 0 \\
\Leftrightarrow & \left(1+\mu_{1}\right) \frac{T+h_{0}^{f}}{2}-\left(1-\mu_{1}\right) \frac{\left(w_{1}^{m}+w_{1}^{f}\right) T+w^{p} h_{0}^{m}}{2 w^{p}} & \geq 0 \\
\Leftrightarrow & \frac{\left(w_{1}^{m}+w_{1}^{f}\right) T-w^{p} T+w^{p}\left(h_{0}^{m}-h_{0}^{f}\right)}{\left(w_{1}^{m}+w_{1}^{f}\right) T+w^{p} T+w^{p}\left(h_{0}^{m}+h_{0}^{f}\right)} & \leq \mu
\end{array}
$$


and

$$
\begin{aligned}
& b^{m *} \quad \geq 0 \\
& \Leftrightarrow \quad\left(2-\mu_{1}\right) \frac{T+h_{0}^{m}}{2}-\mu_{1} \frac{\left(w_{1}^{m}+w_{1}^{f}\right) T+w^{p} h_{0}^{f}}{2 w^{p}} \geq 0 \\
& \Leftrightarrow \quad \frac{2 w^{p}\left(T+h_{0}^{m}\right)}{\left(w_{1}^{m}+w_{1}^{f}\right) T+w^{p}\left(T+h_{0}^{m}+h_{w}^{0}\right)} \quad \geq \mu_{1} .
\end{aligned}
$$

The non-negativity constraints for $b^{m *}$ and $b^{m *}$ can be simultaneously fulfilled only if

$$
\begin{array}{rlrl} 
& \frac{2 w^{p}\left(T+h_{0}^{m}\right)}{\left(w_{1}^{m}+w_{1}^{f}\right) T+w^{p} T+w^{p}\left(h_{0}^{m}+h_{0}^{f}\right)} & \geq \frac{\left(w_{1}^{m}+w_{1}^{f}\right) T-w^{p} T+w^{p}\left(h_{0}^{m}-h_{0}^{f}\right)}{\left(w_{1}^{m}+w_{1}^{f}\right) T+w^{p} T+w^{p}\left(h_{0}^{m}+h_{0}^{f}\right)} \\
\Leftrightarrow & \leq w^{p}+\left(1+\frac{h_{0}^{m}+h_{0}^{f}}{T}\right) w^{p} .
\end{array}
$$

In addition, the duration of professional childcare use needs to be nonnegative, i.e.

$$
\begin{array}{rlrl} 
& & b^{p *} & \\
\Leftrightarrow & \frac{\left(w_{1}^{m}+w_{1}^{f}\right) T-w^{p} T-w^{p}\left(h_{0}^{m}+h_{0}^{f}\right)}{2 w^{p}} & \geq 0 \\
\Leftrightarrow & w_{1}^{m}+w_{1}^{f} & \geq\left(1+\frac{h_{0}^{m}+h_{0}^{f}}{T}\right) w^{p} .
\end{array}
$$

Let us consider, e.g., parameter values such that $w_{1}^{m}=w_{1}^{f}=w^{p}$ and $h_{0}^{m}=h_{0}^{f}=0$. In this case, all non-negativity constraints hold simultaneously if $1 / 3 \leq \mu_{1} \leq 2 / 3$. An interior solution is reached as long as one partner does not have more than twice the power of the other.

\section{Appendix A.2 Proofs of Propositions 1 to 4}

\section{Proof of Proposition 1}

We have

$$
\frac{\partial b^{f *}}{\partial z}=\frac{\partial \mu_{1}(z)}{\partial z} \times \frac{\left(w_{1}^{m}+w_{1}^{f}+w^{p}\right) T+w^{p}\left(h_{0}^{m}+h_{0}^{f}\right)}{2 w^{p}}
$$


The signs of these expressions depend in an obvious way on the sign of $\partial \mu(z) / \partial z$.

\section{Proof of Proposition 2}

(i) $\frac{\partial b^{f *}}{\partial w_{f}^{1}}=\frac{\partial \mu_{1}}{\partial w_{1}^{f}} \times \frac{\left(w_{1}^{m}+w_{1}^{f}+w^{p}\right) T+w^{p}\left(h_{0}^{m}+h_{0}^{f}\right)}{2 w^{p}}-\frac{\left(1-\mu_{1}\right) T}{2 w^{p}}<0$

(ii) analogous

(iii) $\frac{\partial b^{f *}}{\partial w_{1}^{m}}=\frac{\partial \mu_{1}}{\partial w_{1}^{m}} \frac{\left(w_{1}^{m}+w_{1}^{f}+w^{p}\right) T+w^{p}\left(h_{0}^{m}+h_{0}^{f}\right)}{2 w^{p}}-\frac{\left(1-\mu_{1}\right) T}{2 w^{p}}$

(iv) analogous

\section{Proof of Proposition 3}

$$
\frac{\partial b^{p *}}{\partial\left(w_{1}^{m}+w_{1}^{f}\right)}=\frac{T}{2 w^{p}}>0 \quad \text { and } \quad \frac{\partial b^{p *}}{\partial z}=\frac{\partial b^{p *}}{\partial \mu_{1}(z)} \times \frac{\partial \mu_{1}(z)}{\partial z}=0 .
$$

\section{Proof of Proposition 4}

$$
b^{f *}>b^{m *} \quad \Longleftrightarrow \quad \mu_{1}>\frac{1}{2} .
$$




\section{Appendix B The Parental Benefit Statistic 2007}

In Germany in 2007, 675,886 women gave birth to 684,862 children, including multiple births. Since it is the country of domicile of the legal parents that determines entitlement to parental benefit, this figure gives a close estimate of the number of households who are eligible for paid leave. For 658,389 births and 669,139 children a parental benefit application has been approved, meaning that at least one month of paid leave has been taken. Therefore, about 97.5 percent of all births in 2007 appear in the Parental Benefit Statistic 2007. However, the statistic contains information about both parents of a child only if both received parental benefit. One reason why parents might not go on paid leave is that they continue working with more than 30 hours per week or that the family moved abroad after having given birth in Germany.

Tables 1, 2 and 3 provide an overview of parental benefit use for children born in Germany in 2007. Based on a random 65 percent subsample of the Parental Benefit Statistic 2007 provided by the Federal Statistical Office of Germany (2008) we find that in only 35,938 out of 417,832 households, i.e. 8.6 percent, both parents go on paid leave for at least one month (Table 1). Only the mother takes leave in $86.7 \%$ of the families. Not only do few fathers take paternity leave, fathers on leave also take shorter periods off than mothers. 5.3 percent of total parental benefit time is taken by fathers. The corresponding distribution of parental leave time is provided in Table 2. Corner solutions (2 or 12 months) are a favorite for both genders. However, a considerable number of parents does not opt for a corner solution.

One drawback of the administrative data is that households with applications for both parents are likely to be different from those in which only one parent goes on leave. Also, the data contain only indirect and censored income information through the benefit amount. Income is not informative if the option to reduce income is used, which allows parents to reduce working hours to less than 30 hours per week. The benefit is then calculated from the amount by which income has been reduced, and income cannot be calculated from the benefit. Another shortcoming of the statistic is that it does not contain socioeconomic background information 
on, e.g., the employment sector, educational attainment, or the use of daycare facilities. This is in contrast to the dataset the remainder of the paper is based on.

\begin{tabular}{lrr}
\hline \hline Case & Frequency & Fraction \\
\hline Only the mother made use of the parental benefit & 362,368 & $86.7 \%$ \\
Only the father made use of the parental benefit & 19,526 & $4.7 \%$ \\
Both mother and father made use of the parental benefit & 35,938 & $8.6 \%$ \\
\hline Total & 417,832 & $100.0 \%$ \\
\hline \hline
\end{tabular}

Source: Authors' calculations from the Parental Benefit Statistic 2007.

Table 1: Composition of Households that Use Parental Benefit

\begin{tabular}{|c|c|c|c|c|}
\hline \multirow[b]{2}{*}{ Duration in months } & \multicolumn{2}{|c|}{ Women } & \multicolumn{2}{|c|}{ Men } \\
\hline & Frequency & Fraction & Frequency & Fraction \\
\hline 1 & 133 & $0.03 \%$ & 886 & $1.6 \%$ \\
\hline 2 & 1,337 & $0.34 \%$ & 34,323 & $61.9 \%$ \\
\hline 3 & 506 & $0.13 \%$ & 1,578 & $2.8 \%$ \\
\hline 4 & 655 & $0.16 \%$ & 1,250 & $2.3 \%$ \\
\hline 5 & 774 & $0.19 \%$ & 944 & $1.7 \%$ \\
\hline 6 & 1,419 & $0.36 \%$ & 1,513 & $2.7 \%$ \\
\hline 7 & 1,659 & $0.42 \%$ & 1,348 & $2.4 \%$ \\
\hline 8 & 1,904 & $0.48 \%$ & 949 & $1.7 \%$ \\
\hline 9 & 2,341 & $0.59 \%$ & 833 & $1.5 \%$ \\
\hline 10 & 5,426 & $1.36 \%$ & 1,284 & $2.3 \%$ \\
\hline 11 & 5,473 & $1.37 \%$ & 1,751 & $3.2 \%$ \\
\hline 12 & 357,335 & $89.71 \%$ & 8,501 & $15.3 \%$ \\
\hline $13^{*}$ & 7,051 & $1.77 \%$ & 205 & $0.4 \%$ \\
\hline $14^{*}$ & 12,293 & $3.09 \%$ & 99 & $0.2 \%$ \\
\hline Total & 398,306 & $100.0 \%$ & 55,464 & $100.0 \%$ \\
\hline
\end{tabular}

Source: Authors' calculations from the Parental Benefit Statistic 2007.

*Only single parents eligible.

Table 2: Duration of Parental Benefit Use by Gender 


\begin{tabular}{lcccc}
\hline \hline \multicolumn{5}{c}{ Parental Benefit Statistic 2007 (Couples) } \\
Variable & Description & Mean & Std.Dev. & Obs. \\
\hline Parental benefit: Mother & parental benefit duration & 11.15 & 3.09 & 35,938 \\
Parental benefit: Father & in months (range: $1-12)$ & 2.69 & 2.05 & 35,938 \\
Household leave duration & (range: $2-14$ ) & 13.83 & 0.72 & 35,938 \\
Only leave takers considered, i.e. persons who receive benefit for at least one month. \\
Mother's income & (range: $0.3-2.7$ ) & 1.18 & 0.75 & 34,936 \\
Father's income & (range: $0.3-2.7$ ) & 1.43 & 0.82 & 28,481 \\
In tEUR, calculated from & parental benefit amount, left-censored at 0.3, right-censored at 2.7 \\
Mother's income $=300$ & d=1 if income = EUR 300 & 0.23 & 0.43 & 34,936 \\
Father's income $=300$ & & 0.22 & 0.41 & 29,168 \\
Mother's income $=2,700$ & $\mathrm{~d}=1$ if income = EUR 2,700 & 0.05 & 0.22 & 34,936 \\
Father's income $=2,700$ & & 0.12 & 0.32 & 29,168 \\
\hline \hline
\end{tabular}

Note: Unweighted data.

Table 3: Summary Statistics for the Parental Benefit Statistics 2007 


\section{Appendix C Tables}

\begin{tabular}{|c|c|c|c|c|}
\hline \multicolumn{5}{|c|}{ RWI Survey of Children Born in January till April 2007} \\
\hline Variable & Description & Mean & Std.Dev. & Obs. \\
\hline Parental benefit: Mother & parental benefit duration & 10.15 & 3.45 & 4,177 \\
\hline Parental benefit: Father & in months (range: $0-12$ ) & 1.03 & 2.63 & 4,177 \\
\hline Household benefit duration & (range: $0-14$ ) & 11.18 & 2.98 & 4,177 \\
\hline No benefit use: Mother & dummy $(\mathrm{d})=1$ if the num- & 0.08 & 0.27 & 4,177 \\
\hline No benefit use: Father & ber of benefit months $=0$ & 0.76 & 0.43 & 4,177 \\
\hline Professional childcare & $\mathrm{d}=1$ if used & 0.36 & 0.48 & 4,151 \\
\hline Mother's income & (range: $0.08-6.0$ ) & 0.98 & 0.81 & 3,536 \\
\hline Father's income & (range: $0-6.0$ ) & 1.72 & 1.11 & 3,228 \\
\hline Household income & (range: $0.3-12$ ) & 2.78 & 1.44 & 3,130 \\
\hline \multicolumn{5}{|c|}{$\begin{array}{l}\text { Net monthly income in tEUR, means from categories } \\
=\text { EUR } 225 \text { for below EUR } 300 \text { income category; = EUR 6,000 for above EUR 5,000 category }\end{array}$} \\
\hline Age difference & (range: $-25-+35)$ & 3.00 & 4.85 & 4,131 \\
\hline (Father's) Relative income & (range: $0-59$ ) & 3.10 & 3.85 & 3,130 \\
\hline Mother in public sector & $\mathrm{d}=1$ if working in & 0.06 & 0.25 & 4,017 \\
\hline Father in public sector & public sector & 0.07 & 0.24 & 3,523 \\
\hline Mother in private sector & $\mathrm{d}=1$ if working in & 0.53 & 0.50 & 4,017 \\
\hline Father in private sector & private sector & 0.71 & 0.45 & 3,523 \\
\hline Mother is self-employed & $\mathrm{d}=1$ if self-employed & 0.04 & 0.20 & 4,017 \\
\hline Father is self-employed & & 0.11 & 0.31 & 3,523 \\
\hline Mother secondary school & $\mathrm{d}=1$ if highest education & 0.46 & 0.50 & 4,177 \\
\hline Father secondary school & level is secondary school & 0.47 & 0.50 & 4,177 \\
\hline Mother high school & $\mathrm{d}=1$ if highest education & 0.24 & 0.43 & 4,177 \\
\hline Father high school & level is high school & 0.18 & 0.39 & 4,177 \\
\hline Mother college/university & $\mathrm{d}=1$ if highest education & 0.26 & 0.44 & 4,177 \\
\hline Father college/university & level is college/university & 0.28 & 0.45 & 4,177 \\
\hline Age of the oldest child & (range: $0-24$ ) & 2.44 & 3.83 & 4,149 \\
\hline Children & number (range: $1-11$ ) & 1.75 & 0.95 & 4,177 \\
\hline Twins & $\mathrm{d}=1$ if multiple births & 0.02 & 0.14 & 4,177 \\
\hline Mother is foreign & $\mathrm{d}=1$ if not German & 0.11 & 0.31 & 4,142 \\
\hline East & $\mathrm{d}=1$ if living in the East & 0.09 & 0.28 & 4,078 \\
\hline Big city & $\mathrm{d}=1$ if $\geq 100 \mathrm{~T}$ inhabitants & 0.27 & 0.45 & 3,868 \\
\hline
\end{tabular}

Note: Unweighted data.

Table 4: Summary Statistics for the RWI Survey Data 


\begin{tabular}{l|rrr|rrr}
\hline \hline & \multicolumn{3}{|c|}{ Women } & \multicolumn{3}{c}{ Men } \\
Income & Mean & Std.Err. & Obs. & Mean & Std.Err. & Obs. \\
\hline 300 or less & 11.47 & 0.05 & 932 & 6.49 & 0.39 & 146 \\
$301-1,000$ & 11.13 & 0.06 & 849 & 4.71 & 0.36 & 120 \\
$1,001-1,500$ & 10.85 & 0.06 & 736 & 3.85 & 0.30 & 143 \\
$1,501-2,000$ & 10.75 & 0.10 & 379 & 3.49 & 0.23 & 169 \\
$2,001-2,699$ & 10.50 & 0.16 & 220 & 3.69 & 0.25 & 158 \\
2700 or more & 9.67 & 0.30 & 110 & 3.13 & 0.28 & 84 \\
\hline Total & 11.03 & 0.03 & 3,226 & 4.27 & 0.13 & 820 \\
\hline \hline
\end{tabular}

Source: Authors' calculations from the RWI survey.

Only leave takers (benefit duration $\geq 1$ month).

Table 5: Average Benefit Duration among Leave Takers by Monthly Net Income and Gender 


\begin{tabular}{|c|c|c|c|c|}
\hline \multirow{2}{*}{$\begin{array}{l}\text { Leave duration of the } \\
\text { Estimation Method }\end{array}$} & \multicolumn{2}{|c|}{ Mother } & \multicolumn{2}{|c|}{ Father } \\
\hline & Logit QMLE & OLS & Logit QMLE & OLS \\
\hline Father's relative income & $\begin{array}{c}0.0063^{*} \\
(0.0015)\end{array}$ & $\begin{array}{c}0.0047^{*} \\
(0.0010)\end{array}$ & $\begin{array}{c}-0.0046^{*} \\
(0.0012)\end{array}$ & $\begin{array}{c}-0.0047^{*} \\
(0.0010)\end{array}$ \\
\hline Age difference & $\begin{array}{c}0.0028^{*} \\
(0.0011)\end{array}$ & $\begin{array}{c}0.0032^{*} \\
(0.0012)\end{array}$ & $\begin{array}{c}-0.0019^{*} \\
(0.0008)\end{array}$ & $\begin{array}{c}-0.0032^{*} \\
(0.0012)\end{array}$ \\
\hline Household income (in tEUR) & $\begin{array}{c}-0.0012 \\
(0.0036)\end{array}$ & $\begin{array}{c}0.0015 \\
(0.0042)\end{array}$ & $\begin{array}{c}0.0014 \\
(0.0023)\end{array}$ & $\begin{array}{c}-0.0015 \\
(0.0042)\end{array}$ \\
\hline Total household leave duration & $\begin{array}{c}0.0378^{*} \\
(0.0011)\end{array}$ & $\begin{array}{c}0.0596^{*} \\
(0.0019)\end{array}$ & $\begin{array}{c}0.0303^{*} \\
(0.0016)\end{array}$ & $\begin{array}{c}0.0237^{*} \\
(0.0019)\end{array}$ \\
\hline SER $^{a)}$ & 0.72 & 0.20 & 1.34 & 0.20 \\
\hline$R^{2}$ & 0.44 & 0.37 & 0.24 & 0.13 \\
\hline $\begin{array}{l}\text { Testing joint significance } \\
\left.\text { of sector dummies }{ }^{b}\right) \\
\mathrm{p} \text { value } \\
\left.\text { of education dummies }{ }^{b}\right) \\
\mathrm{p} \text { value }\end{array}$ & $\begin{array}{c}31.25 \\
{[0.00]^{*}} \\
5.19 \\
{[0.52]}\end{array}$ & $\begin{array}{c}5.27 \\
{[0.00]^{*}} \\
1.42 \\
{[0.20]}\end{array}$ & $\begin{array}{c}29.13 \\
{[0.00]^{*}} \\
6.56 \\
{[0.36]}\end{array}$ & $\begin{array}{c}5.27 \\
{[0.00]^{*}} \\
1.42 \\
{[0.20]}\end{array}$ \\
\hline $\begin{array}{l}\text { Distribution factor tests (based } \\
\text { distribution factor ratio }=0^{c} \\
\text { p value } \\
95 \% \text { CI for difference in ratios }\end{array}$ & $\begin{array}{c}\text { on logit QML } \\
4.85 \\
{[0.03]^{*}}\end{array}$ & $\begin{array}{c}4.91 \\
{[0.03]^{*}}\end{array}$ & $\begin{array}{r}\text { ons) } \\
4.24 \\
{[0.04]^{*}} \\
.21,0.23]\end{array}$ & $\begin{array}{c}4.91 \\
{[0.03]^{*}}\end{array}$ \\
\hline
\end{tabular}

Regression results from the RWI survey with robust standard errors in parentheses. Sample size is 2,408. The dependent variables are the number of parental benefit months divided by 12 . For logit QMLE marginal effects with all variables at means are shown. Control variables for parents in public sector, self-employed, not working (reference group is private sector), parents' education, number of children in the household, twins, foreign mother, parents living in East Germany, and living in a big city are included.

a: Standard error of the regression; for QMLE the SER is defined in terms of weighted residuals.

b: Wald statistic from $F$ distribution (OLS) and chi-square distribution (QMLE).

c: Nonlinear Wald test on significance of the ratio of distribution factor coefficients.

$\mathrm{d}$ : Bootstrapped confidence interval for the difference between the ratios of distribution factor coefficients across models.

*: Significantly different from zero on the $5 \%$ level (two-sided test).

Table 6: Tests of Collective Rationality in Parental Leave Sharing 


\begin{tabular}{|c|c|c|}
\hline & \multicolumn{2}{|c|}{ Professional childcare use } \\
\hline Estimation Method & Logit QMLE & OLS \\
\hline Father's relative income & $\begin{array}{c}-0.0022 \\
(0.0032)\end{array}$ & $\begin{array}{c}-0.0026 \\
(0.0029)\end{array}$ \\
\hline Age difference & $\begin{array}{l}0.0037 \\
(0.0023)\end{array}$ & $\begin{array}{c}0.0034 \\
(0.0021)\end{array}$ \\
\hline Household income (in tEUR) & $\begin{array}{c}0.0204^{*} \\
(0.0092)\end{array}$ & $\begin{array}{r}0.0210^{*} \\
(0.0089)\end{array}$ \\
\hline Total household leave duration & $\begin{array}{c}-0.0111^{*} \\
(0.0041)\end{array}$ & $\begin{array}{c}-0.0104^{*} \\
(0.0039)\end{array}$ \\
\hline $\begin{array}{l}\mathrm{SER}^{\mathrm{a})} \\
R^{2}\end{array}$ & $\begin{array}{l}1.00 \\
0.09\end{array}$ & $\begin{array}{l}0.46 \\
0.09\end{array}$ \\
\hline $\begin{array}{l}\text { Testing joint significance } \\
\left.\text { of sector dummies }{ }^{b}\right) \\
\mathrm{p} \text { value } \\
\left.\text { of education dummies }{ }^{b}\right) \\
\mathrm{p} \text { value }\end{array}$ & $\begin{array}{c}32.45 \\
{[0.00]^{*}} \\
39.50 \\
{[0.00]^{*}}\end{array}$ & $\begin{array}{c}5.51 \\
{[0.00]^{*}} \\
6.73 \\
{[0.00]^{*}}\end{array}$ \\
\hline $\begin{array}{l}\text { Distribution factor tests (ba } \\
\left.\text { distribution factor ratio }=0^{c}\right) \\
\text { p value }\end{array}$ & $\begin{array}{c}\text { ed on logit } \mathrm{QM} \\
0.44 \\
{[0.51]}\end{array}$ & $\begin{array}{l}\text { ions) } \\
0.64 \\
{[0.42]}\end{array}$ \\
\hline
\end{tabular}

Regression results from the RWI survey with robust standard errors in parentheses. Sample size is 2,408 . The dependent variable is a dummy equal to 1 if professional childcare is used. For logit QMLE marginal effects with all variables at means are shown. Control variables for parents in public sector, self-employed, not working (reference group is private sector), parents' education, number of children in the household, twins, foreign mother, living in East Germany, and living in a big city are included.

a: Standard error of the regression; for QMLE the SER is defined in terms of weighted residuals.

b: Wald statistic from F distribution (OLS) and chi-square distribution (QMLE). c: Nonlinear Wald test on significance of the ratio of distribution factor coefficients. *: Significantly different from zero on the $5 \%$ level (two-sided test).

Table 7: Professional Childcare Use Estimations 


\begin{tabular}{|c|c|c|c|c|}
\hline $\begin{array}{l}\text { Leave duration of the } \\
\text { Estimation Method }\end{array}$ & \multicolumn{2}{|c|}{$\begin{array}{c}\text { Mother } \\
\text { Logit QMLE }\end{array}$} & \multicolumn{2}{|c|}{$\begin{array}{c}\text { Father } \\
\text { Tobit }\end{array}$} \\
\hline Log(father's income) & $\begin{array}{c}0.0240^{*} \\
(0.0050)\end{array}$ & $\begin{array}{c}-0.0138^{*} \\
(0.0036)\end{array}$ & $\begin{array}{c}0.8029^{*} \\
(0.1841)\end{array}$ & $\begin{array}{c}-1.5015^{*} \\
(0.2427)\end{array}$ \\
\hline Log(mother's income) & $\begin{array}{c}-0.0386^{*} \\
(0.0084)\end{array}$ & $\begin{array}{c}0.0204^{*} \\
(0.0054)\end{array}$ & $\begin{array}{c}-1.4137^{*} \\
(0.2797)\end{array}$ & $\begin{array}{c}1.6227^{*} \\
(0.3184)\end{array}$ \\
\hline Age difference & $\begin{array}{c}0.0024^{*} \\
(0.0011)\end{array}$ & $\begin{array}{c}-0.0018^{*} \\
(0.0008)\end{array}$ & $\begin{array}{r}0.0942^{*} \\
(0.0355)\end{array}$ & $\begin{array}{c}-0.1340^{*} \\
(0.0538)\end{array}$ \\
\hline Total household leave duration & $\begin{array}{c}0.0376^{*} \\
(0.0011)\end{array}$ & $\begin{array}{c}0.0302^{*} \\
(0.0016)\end{array}$ & $\begin{array}{c}1.5502^{*} \\
(0.0697)\end{array}$ & $\begin{array}{c}1.7100^{*} \\
(0.1953)\end{array}$ \\
\hline SER ${ }^{a)}$ & 0.73 & 1.18 & & \\
\hline$R^{2} /$ Pseudo $R^{2}$ & 0.45 & 0.25 & 0.14 & 0.11 \\
\hline $\begin{array}{l}\left.\text { Proportionality test }{ }^{b}\right) \\
\text { p value }\end{array}$ & $\begin{array}{c}2.00 \\
{[0.16]}\end{array}$ & $\begin{array}{l}1.10 \\
{[0.29]}\end{array}$ & $\begin{array}{c}3.15 \\
{[0.08]}\end{array}$ & $\begin{array}{c}0.09 \\
{[0.76]}\end{array}$ \\
\hline $\begin{array}{l}\text { Joint proportionality test }{ }^{c)} \\
\text { p value }\end{array}$ & \multicolumn{2}{|c|}{$\begin{array}{c}\chi^{2}(2)=2.77 \\
{[0.73]}\end{array}$} & \multicolumn{2}{|c|}{$\begin{array}{c}\chi^{2}(2)=8.17 \\
{[0.31]}\end{array}$} \\
\hline
\end{tabular}

Regression results from the RWI survey with robust standard errors in parentheses. Sample size is 2,361 . The dependent variables are the number of parental benefit months divided by 12 . For logit QMLE marginal effects with all variables at means are shown. Control variables for parents in public sector, self-employed, not working (reference group is private sector), parents' education, number of children in the household, twins, foreign mother, parents living in East Germany, and living in a big city are included.

a: Standard error of the regression; for QMLE the SER is defined in terms of weighted residuals.

b: Testing the hypothesis: $\log$ (mother's income $)+\log$ (father's income $)=0 . \mu$ is assumed to be increasing in father's income and decreasing in mother's income.

c: Test $\log ($ mother's income $)+\log ($ father's income $)=0$ jointly across models [bootstrapped $\mathrm{p}$ value].

d: Tobit estimations with a lower limit at 0 and an upper limit at 12 parental benefit months.

*: Significantly different from zero on the $5 \%$ level (two-sided test).

Table 8: Income Effects 


\begin{tabular}{|c|c|c|c|c|}
\hline $\begin{array}{l}\text { Leave duration of the } \\
\text { Estimation Method } \\
\text { Sample size }\end{array}$ & \multicolumn{2}{|c|}{$\begin{array}{c}\text { Mother } \\
\text { Logit QMLE } \\
632 \text { Obs. }\end{array}$} & $\begin{array}{r}\mathrm{Lo} \\
8\end{array}$ & $\begin{array}{l}\text { aer } \\
\text { QMLE } \\
\text { Obs. }\end{array}$ \\
\hline Father's relative income & & $\begin{array}{c}0.0009 \\
(0.0040)\end{array}$ & & $\begin{array}{c}-0.0052 \\
(0.0027)\end{array}$ \\
\hline Age difference & $\begin{array}{l}0.0020 \\
(0.0021)\end{array}$ & & $\begin{array}{c}-0.0006 \\
(0.0013)\end{array}$ & \\
\hline Household income (in tEUR) & $\begin{array}{c}-0.0079 \\
(0.0063)\end{array}$ & $\begin{array}{c}-0.0075 \\
(0.0064)\end{array}$ & $\begin{array}{c}-0.0128^{*} \\
(0.0055)\end{array}$ & $\begin{array}{c}-0.0125^{*} \\
(0.0055)\end{array}$ \\
\hline Partner's leave duration & $\begin{array}{c}-0.1503^{*} \\
(0.0396)\end{array}$ & $\begin{array}{c}-0.1476^{*} \\
(0.0395)\end{array}$ & $\begin{array}{c}-0.1118^{*} \\
(0.0203)\end{array}$ & $\begin{array}{c}-0.1138^{*} \\
(0.0203)\end{array}$ \\
\hline Partner's leave duration measure ${ }^{a)}$ & $\begin{array}{c}0.2591^{*} \\
(0.0969)\end{array}$ & $\begin{array}{c}0.2529^{*} \\
(0.0967)\end{array}$ & $\begin{array}{c}0.1742^{*} \\
(0.0460)\end{array}$ & $\begin{array}{c}0.1801^{*} \\
(0.0459)\end{array}$ \\
\hline SER $^{b)}$ & 0.52 & 0.52 & 0.52 & 0.52 \\
\hline$R^{2}$ & 0.51 & 0.51 & 0.57 & 0.57 \\
\hline
\end{tabular}

Regression results from the RWI survey with robust standard errors in parentheses. The dependent variables are the number of parental benefit months divided by 12 . For logit QMLE marginal effects with all variables at means are shown. Controls for parents' in public sector, self-employed, not working (reference group is private sector), parents' education, number of children in the household, twins, foreign mother, parents living in East Germany, and living in a big city are included.

a: $\log [($ partner's leave duration/12) / (1 - (partner's leave duration/12))].

Defined for leave durations $>0$ and $<12$.

b: Standard error of the regression defined in terms of weighted residuals.

*: Significantly different from zero on the $5 \%$ level (two-sided test).

Table 9: z-Conditional Demands 


\begin{tabular}{|c|c|c|c|c|}
\hline \multirow{2}{*}{$\begin{array}{l}\text { Leave duration of the } \\
\text { Estimation Method } \\
\text { Sample size } \\
\text { Father's relative income }\end{array}$} & \multicolumn{2}{|c|}{$\begin{array}{c}\text { Mother } \\
\text { Logit QMLE } \\
\text { First births (1,367 Obs.) }\end{array}$} & \multicolumn{2}{|c|}{$\begin{array}{c}\text { Father } \\
\left.\text { Tobit estimations }{ }^{\mathrm{c}}\right) \\
\text { Full sample }(2,408 \text { Obs. })\end{array}$} \\
\hline & $\begin{array}{c}0.0080^{*} \\
(0.0035)\end{array}$ & $\begin{array}{c}-0.0060^{*} \\
(0.0024)\end{array}$ & $\begin{array}{l}0.1952^{*} \\
(0.00503)\end{array}$ & $\begin{array}{c}-0.3666^{*} \\
(0.0767)\end{array}$ \\
\hline Age difference & $\begin{array}{c}0.0027^{*} \\
(0.0013)\end{array}$ & $\begin{array}{c}-0.0025^{*} \\
(0.0011)\end{array}$ & $\begin{array}{c}0.1077^{*} \\
(0.0355)\end{array}$ & $\begin{array}{c}-0.1617^{*} \\
(0.00543)\end{array}$ \\
\hline Household income (in tEUR) & $\begin{array}{c}-0.0060 \\
(0.0047)\end{array}$ & $\begin{array}{l}0.0048 \\
(0.0035)\end{array}$ & $\begin{array}{c}-0.0734 \\
(0.1193)\end{array}$ & $\begin{array}{c}-0.2092 \\
(0.1584)\end{array}$ \\
\hline Total household leave duration & $\begin{array}{c}0.0383^{*} \\
(0.0014)\end{array}$ & $\begin{array}{c}0.0316^{*} \\
(0.0021)\end{array}$ & $\begin{array}{c}1.5686^{*} \\
(0.0703)\end{array}$ & $\begin{array}{c}1.7563^{*} \\
(0.2014)\end{array}$ \\
\hline$R^{2} /$ Pseudo $R^{2}$ & 0.43 & 0.26 & 0.13 & 0.11 \\
\hline $\begin{array}{l}\text { Distribution factor tests (basec } \\
\text { distribution factor ratio }=0^{\text {a) }} \\
\text { p value }\end{array}$ & $\begin{array}{l}\text { on logit } \\
2.05 \\
{[0.15]}\end{array}$ & $\begin{array}{l}\text { LE estimatio } \\
2.42 \\
{[0.12]}\end{array}$ & $\begin{array}{l}\text { s) } \\
5.56 \\
{[0.02]^{*}}\end{array}$ & $\begin{array}{c}5.95 \\
{[0.01]^{*}}\end{array}$ \\
\hline $95 \%$ CI for difference in ratios b) & \multicolumn{2}{|c|}{$[-0.66,0.32]$} & \multicolumn{2}{|c|}{$[-0.19,0.53]$} \\
\hline
\end{tabular}

Regression results from the RWI survey with robust standard errors in parentheses. The dependent variables are the number of parental benefit months. For logit QMLE leave durations are divided by 12 (not for Tobit estimations). Marginal effects with all variables at means are presented. Controls for parents' in public sector, self-employed, not working (reference group is private sector), parents' education, number of children in household, twins, foreign mother, parents living in East Germany, and living in a big city are included.

a: Nonlinear Wald test on significance of the ratio of distribution factor coefficients.

b: Bootstrapped confidence interval for the difference between ratios of distribution factor coefficients.

c: Tobit estimations with a lower limit at 0 and an upper limit at 12 parental benefit months.

*: Significantly different from zero on the $5 \%$ level (two-sided test).

Table 10: First Birth Restricted Sample and Tobit Estimations 
Institut de Recherches Économiques et Sociales

Université catholique de Louvain

Place Montesquieu, 3

1348 Louvain-la-Neuve, Belgique 